\title{
Active Distribution Network Modeling for Enhancing Sustainable Power System Performance; a Case Study in Egypt
}

\author{
Ali A. Radwan ${ }^{1,2} \oplus$, Ahmed A. Zaki Diab ${ }^{1, *} \mathbb{C}$, Abo-Hashima M. Elsayed ${ }^{1}$, \\ Hassan Haes Alhelou ${ }^{3, *(D)}$ and Pierluigi Siano $4, * \mathbb{D}$ \\ 1 Electrical Engineering Department, Faculty of Engineering, Minia University, Minia 61517, Egypt; \\ alyshafy@gmail.com (A.A.R.); dr_mostafa555@yahoo.com (A.-H.M.E.) \\ 2 Egyptian Electricity Holding Company, Middle Egypt DisCo., Minia 61111, Egypt \\ 3 Faculty Member at the Department of Electrical Power Engineering, Tishreen University, Lattakia, Syria \\ 4 Department of Management \& Innovation Systems, University of Salerno, 84084 Salerno, Italy \\ * Correspondence: a.diab@mu.edu.eg (A.A.Z.D.); h.haesalhelou@gmail.com (H.H.A.); psiano@unisa.it (P.S.)
}

Received: 1 October 2020; Accepted: 26 October 2020; Published: 29 October 2020

check for updates

\begin{abstract}
The remarkable growth of distributed generation (DG) penetration inside electrical power systems turns the familiar passive distribution networks (PDNs) into active distribution networks (ADNs). Based on the backward/forward sweep method (BFS), a new power-flow algorithm was developed in this paper. The algorithm is flexible to handle the bidirectional flow of power that characterizes the modern ADNs. Models of the commonly used distribution network components were integrated with the developed algorithm to form a comprehensive tool. This tool is valid for modeling either balanced or unbalanced ADNs with an unlimited number of nodes or laterals. The integrated models involve modeling of distribution lines, losses inside distribution transformers, automatic voltage regulators (AVRs), DG units, shunt capacitor banks (SCBs) and different load models. To verify its validity, the presented algorithm was first applied to the unbalanced IEEE 37-node standard feeder in both passive and active states. Moreover, the algorithm was then applied to a balanced $22 \mathrm{kV}$ real distribution network as a case study. The selected network is located in a remote area in the western desert of Upper Egypt, far away from the Egyptian unified national grid. Accordingly, the paper examines the current and future situation of the Egyptian electricity market. Comparison studies between the performance of the proposed ADNs and the classical PDNs are discussed. Simulation results are presented to demonstrate the effectiveness of the proposed ADNs in preserving the network assets, improving the system performance and minimizing the power losses.
\end{abstract}

Keywords: modeling; distributed generation (DG); active distribution network (ADN); planning; automatic voltage regulator (AVR); backward/forward sweep (BFS)

\section{Introduction}

Electrical power system modeling is a significant approach for the optimization of planning, designing or operating that system technically and economically. Therefore, the invention of the digital computer in the 1940s encouraged scholars to start solving different network troubles by different algorithms and techniques [1-8]. Many algorithms such as the Newton-Raphson (NR), Gauss-Seidel (GS) and fast decoupled (FD) are appropriately validated for simulating transmission systems (TSs) [4-8]. Nevertheless, the distribution systems are distinguished in numerous features. High values of the resistance-to-reactance ratio, $\mathrm{R} / \mathrm{X}$, are distinctive in distribution voltage levels while these values are decreasing as the voltage level increases in TSs. All TSs consist of tightly meshed networks whereas distribution systems may have radial or weakly meshed configurations. 
Generator nodes in distribution systems may be PQ, PV or composite nodes while generator nodes in transmission systems are mostly PV nodes. The PQ node is the node at which voltage can be regulated by controlling the real and reactive powers (P and Q) independently. PV node is the node at which generated real power and voltage magnitude $(\mathrm{P}$ and $\mathrm{V})$ can be controlled independently. Table 1 itemizes the differences between distribution and transmission power systems concerning the power flow analysis. Accordingly, conventional presented algorithms may not be suitable for solving the problems of radial distribution networks (DNs) with an acceptable convergence [9-15]. The distinctive radial structure of DNs is used as a basic feature to simulate DNs using the technique known as backward/forward sweep (BFS) [16-19].

Table 1. Assessment of distribution and transmission power systems.

\begin{tabular}{ccc}
\hline Feature & Distribution System & Transmission System \\
\hline Structure & Radial/Weakly meshed & Tightly meshed \\
\hline Types of Load & $\begin{array}{c}\text { Constant Power }(\mathrm{CP}) / \text { Constant Current } \\
(\mathrm{CC}) / \text { Constant Impedance }(\mathrm{CI}) / \text { Composite }\end{array}$ & Mostly CP only \\
\hline Symmetricity & Unbalanced/Balanced & Balanced \\
\hline R/X Ratio & High & Very low \\
\hline Generator Nodes & PQ/PV/Composite & Mostly PV only \\
\hline
\end{tabular}

Recently, distribution utilities have faced new challenges concerning environmental conservation, power sustainability and energy market economics. Therefore, a remarkable growth in the penetration rate of distributed generation (DG) units inside power DNs has been informed [20]. This growth turns the classical passive distribution networks (PDNs) into active distribution networks (ADNs) concerning the bidirectional flow of power [21-23]. A popular definition of the ADN was presented in [24] by the CIGRE working group C6.19. The new topology of ADNs necessitates modern simulation of network impedances under different grid conditions $[25,26]$. The newly added components lead to the need of modeling balanced and/or unbalanced ADNs using grid-connected inverters [27]. Reference [28] presents a review of power distribution planning models in ADNs where a lack of modeling networks containing an automatic voltage regulator (AVR) as a voltage control unit is noticed. Moreover, the previously presented models neglect one important source of losses in real DNs, namely power dissipated inside distribution transformers. This paper tries to fill this gap and presents a comprehensive power-flow program based on the BFS technique. The program is embedded with models of the commonly used DN components.

In this paper, a real Egyptian DN is highlighted as a practical application of the proposed program. The current and future situation of the Egyptian electricity market is examined in Section 2 focusing on the case-study region. Section 3 presents the modeling of distribution lines, losses inside distribution transformers, AVR groups, DG units, shunt capacitor banks (SCBs) and different load models. The integration of these models with the proposed power-flow algorithm is described in Section 4. Simulation results are discussed in Section 5 focusing on the analysis of two different networks before and after their conversion to ADNs. Eventually, Section 6 summarizes the main conclusions.

\section{Examination of the Studied Real Case Study in Egypt}

Although Egypt is rich in various renewable energy sources, these sources have not been optimally exploited yet [29]. Most of the generated electricity in Egypt is thermally produced from either gas, steam or combined cycle. Another source of electricity in Egypt is hydroelectric power derived by exploiting the energy of falling water through the river Nile dams. Figure 1 shows the renewable energy contribution compared to other electricity sources in the Egyptian electricity market in the fiscal year 2018-2019. The percentage of the installed capacity of renewable resources to the total electrical 
installed capacity in Egypt does not exceed 3.8\%. The percentage of generated renewable energy to the total generated energy in Egypt also does not exceed $2.3 \%$.

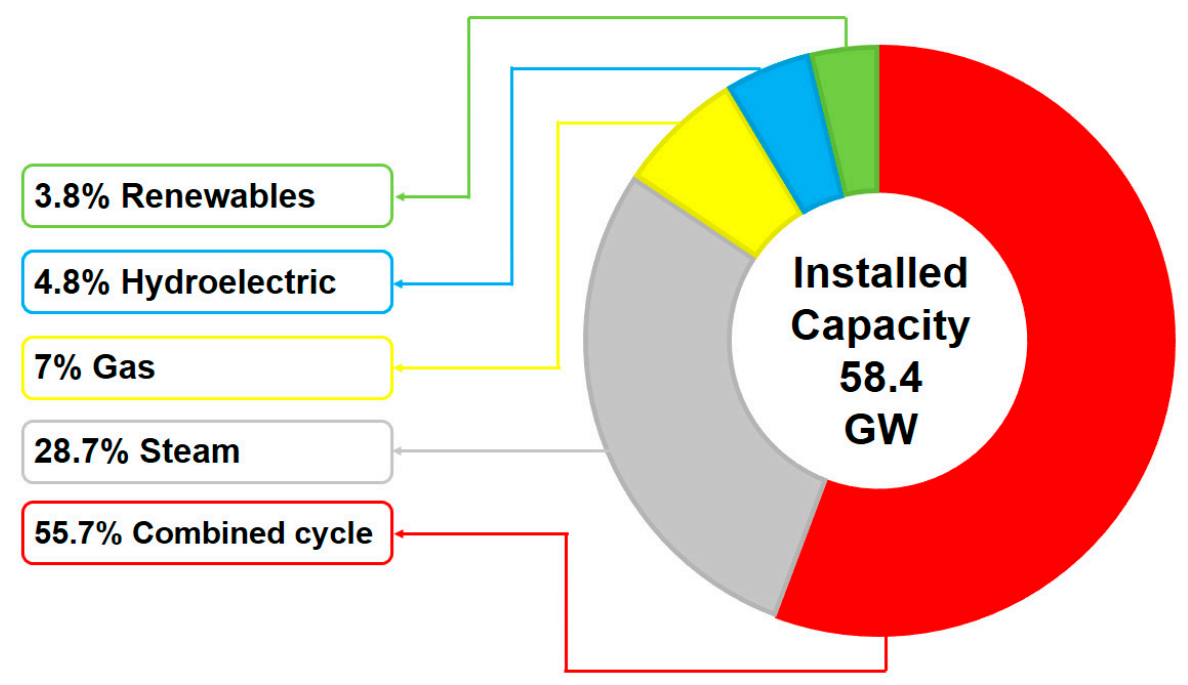

(a) Installed capacity

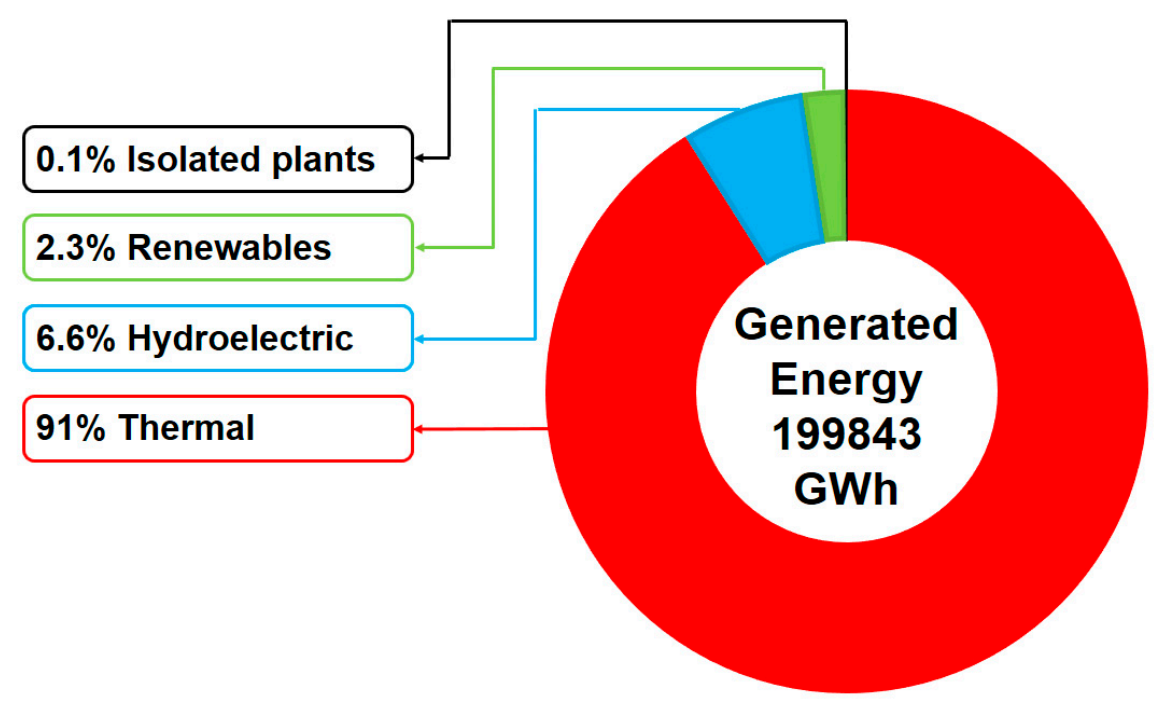

(b) Generated energy

Figure 1. Egyptian electricity sources in the fiscal year 2018-2019.

The strategy of the Egyptian electricity sector represented by the Electricity Holding Company (EEHC) aims to increase the contribution of renewable energy in Egypt to 42\% by 2035. The EEHC has modified its policies to encourage private investments in renewable power generation projects. This explains the recently remarked relative increase in the installed capacity of renewable power sources. According to the recently published report of the EEHC, the contribution of renewable power sources increased during the last year from $2 \%$ to $3.8 \%$ of the total installed capacity. Regarding the actual generated energy, renewable energy increased during the last year from $1.46 \%$ to $2.3 \%$ of the total generated energy. 
The New Valley region in the western desert of Upper Egypt is one of the promising regions on which development strategies are based according to Egypt's Vision 2030. This region is well-known for its richness in various types of mineral wealth, soil fertility and the availability of groundwater. The recently published solar atlas of Egypt indicates that this region has another treasure. Figure 2 illustrates the yearly sum of global solar radiation over New Valley as compared to other Egyptian regions. The average yearly solar radiation over New Valley ranges between 2800 and $3200 \mathrm{kWh} / \mathrm{m}^{2}$ according to the average values during the last 20 years. The daily duration of sunshine fluctuates between 9 and $11 \mathrm{~h}$ [29]. This climate gives New Valley the priority for investment in renewable energy projects.

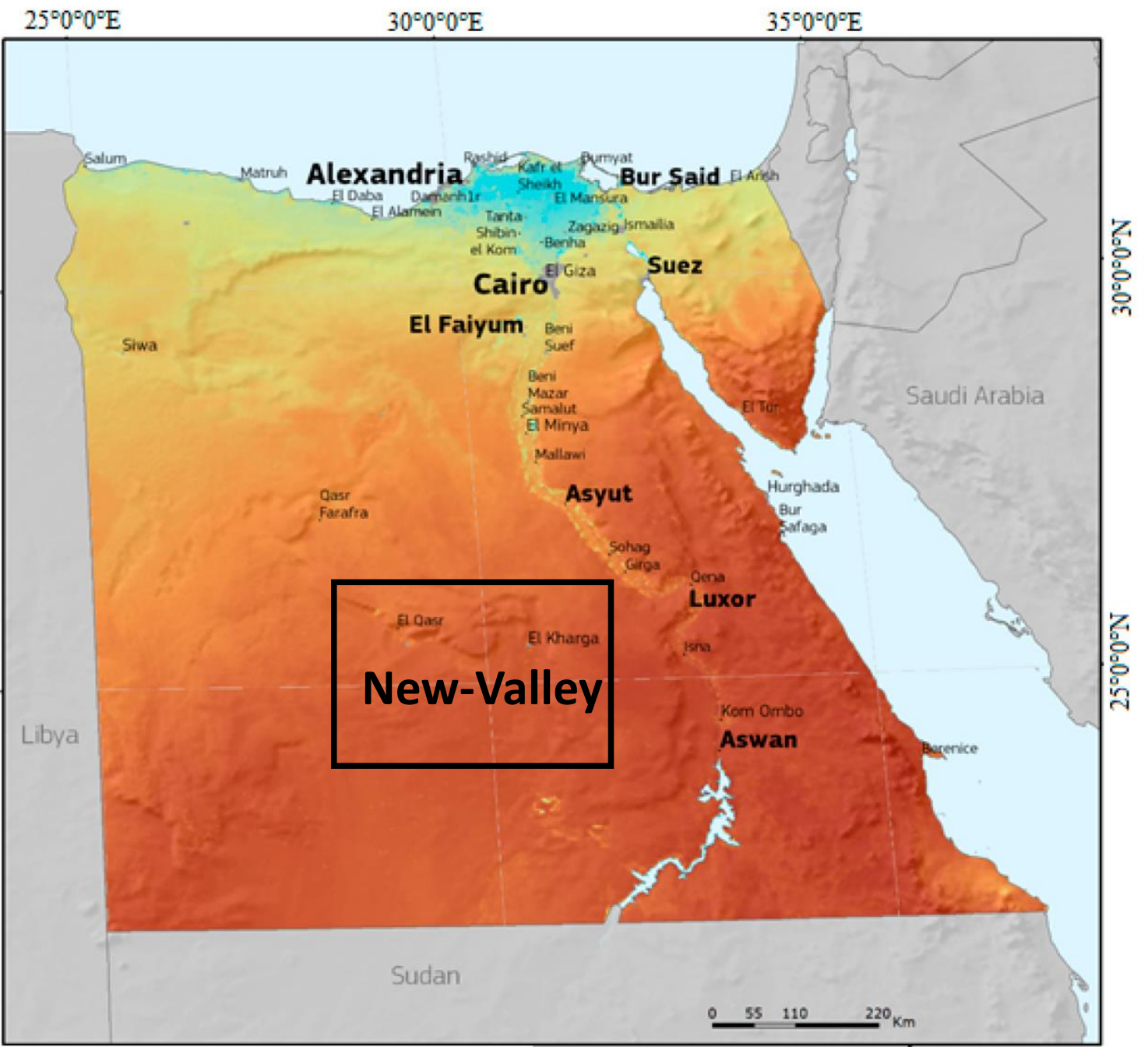

Yearly sum of global solar radiation $\left[\mathrm{kWh} / \mathrm{m}^{2}\right]$

$<2000 \quad 2200 \quad 2400 \quad 2800 \quad 3000$

Figure 2. The yearly sum of global solar radiation in Egypt.

Despite the efforts made by the EEHC to supply that region with electrical energy, the long distance between load demands and the existing unified national grid affects the power quality and makes connecting these loads to the unified national grid an uneconomic process. Therefore, some loads (around $38.5 \mathrm{MW}$ ) are still not connected to the unified national grid. These isolated loads include 32.5 MW powered by diesel generators while only $6 \mathrm{MW}$ are supplied by solar energy. 
Two far demand areas (Arbien and Max) located in the New Valley region were selected as a case study. The two areas are electrically fed by the same DN. Figure 3 illustrates the location of this Upper Egypt distribution network (UEDN) compared to the path of the Egyptian unified electrical grid. The single-line diagram of the existing network that supplies these areas with electrical energy is shown in Figure 4. The selected areas are supplied from the Kharja substation through the transformer $5 \mathrm{~T}$ of capacity $25 \mathrm{MVA}$ with a transformation ratio of $66 / 22 \mathrm{kV}$. The Kharja substation is connected to the extra-high-voltage grid through the Abo Tartor substation 220/66 kV by two circuits. Each circuit is constructed by an overhead line of aluminum conductors steel reinforced (ACSR) with a cross-sectional area of $380 / 50 \mathrm{~mm}^{2}$ and $48 \mathrm{~km}$ in length. A detailed description of the studied network and its load distribution is given in Section 5.2.

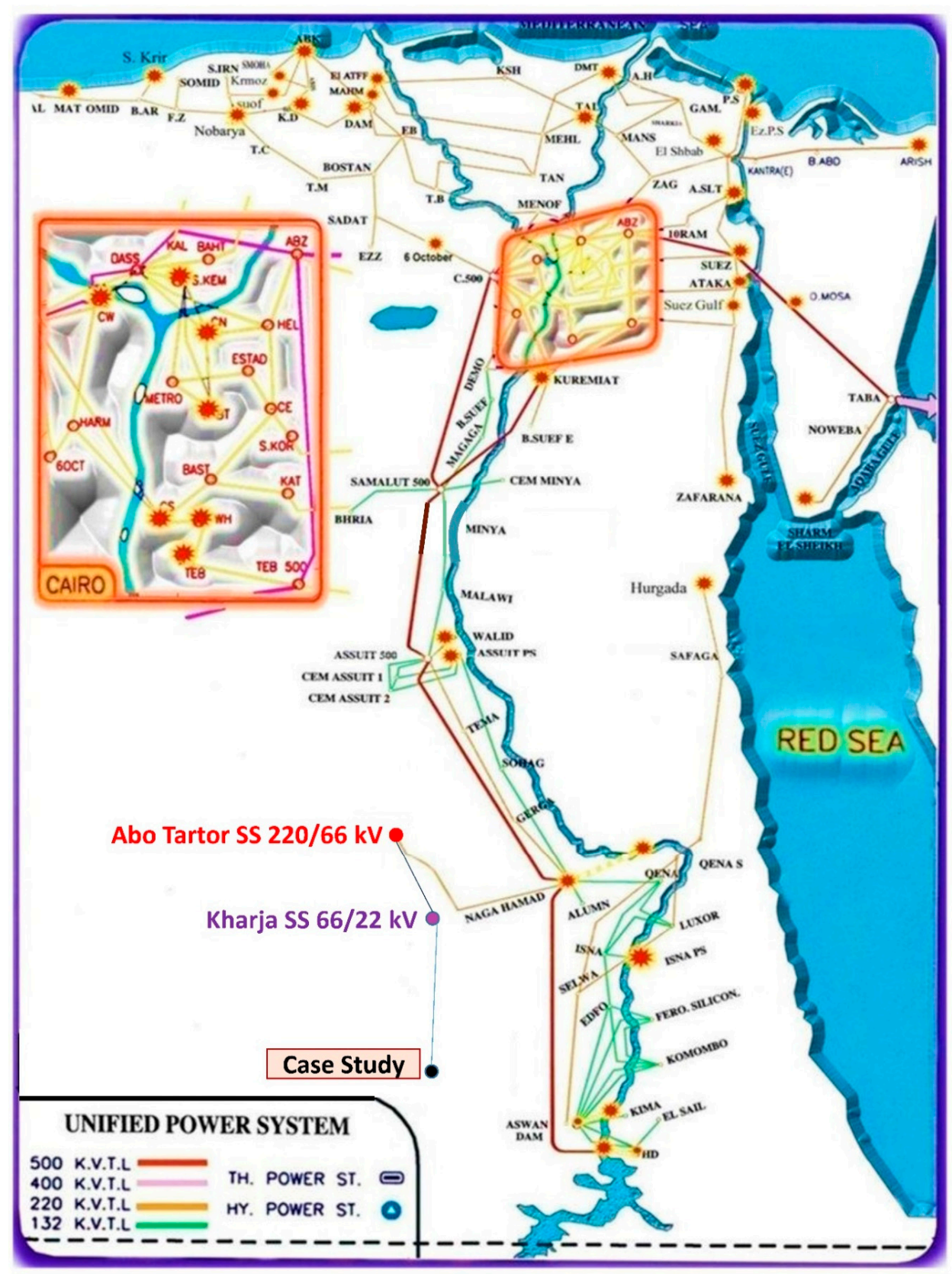

Figure 3. Case study location compared to the Egyptian unified national grid. "TH. POWER ST." is referred to thermal power stations, "HY. POWER ST." is referred to Hydraulic Power Station and "SS" is referred to Substation. 


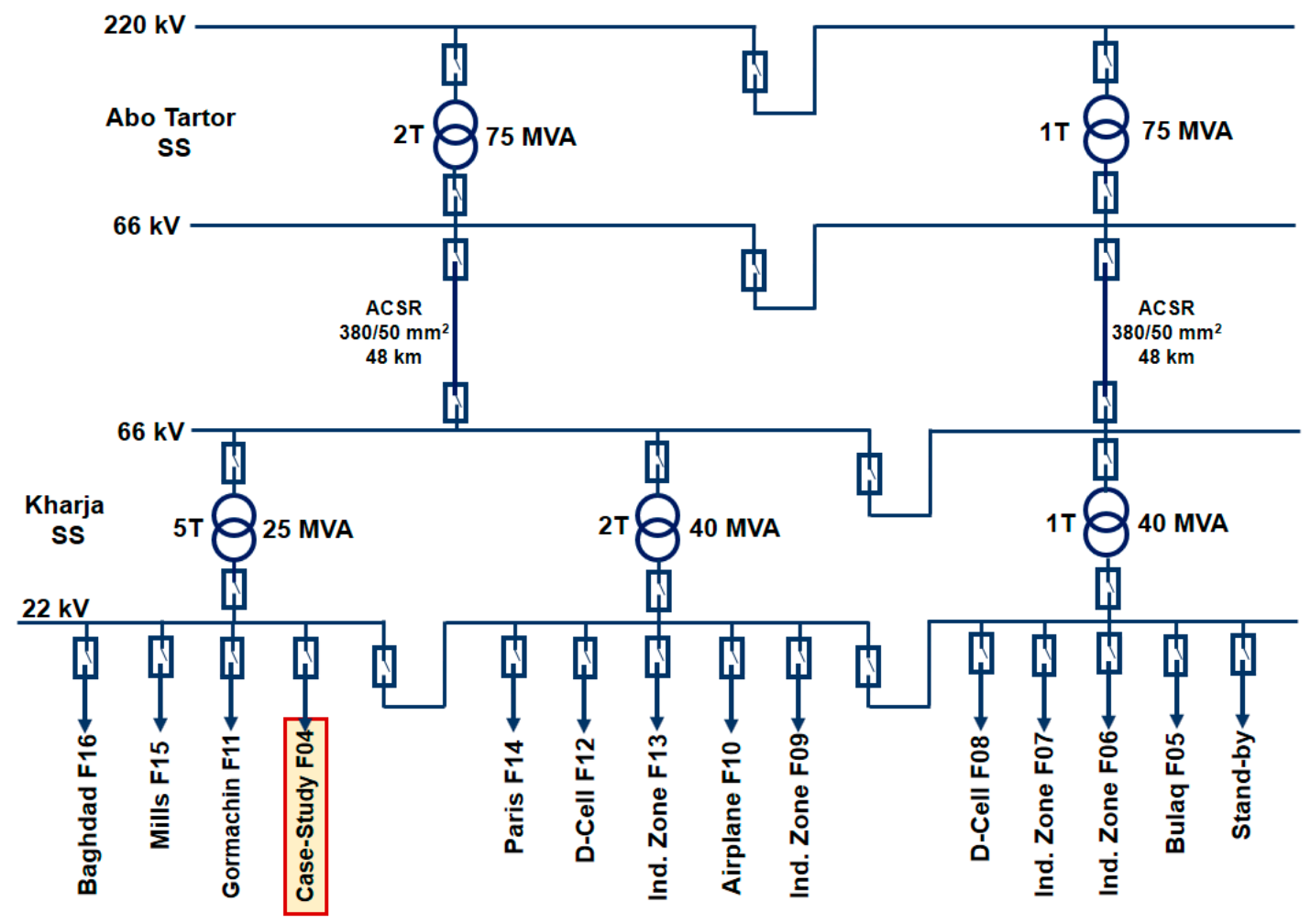

Figure 4. Single-line diagram of the case-study supply system.

\section{Modeling of DN Components}

The realization of any power-flow algorithm requires first an establishment of a model for each component of the DN. A component model is mainly built with physical and electrical specifications given in the manufacturing catalogs. Figure 5 shows a simplified single-line diagram and an electric equivalent of an ADN portion containing DG, distribution transformer, SCB and AVR connected to node $\mathrm{k}$. The following subsections describe the modeling of each element in this segment [30].

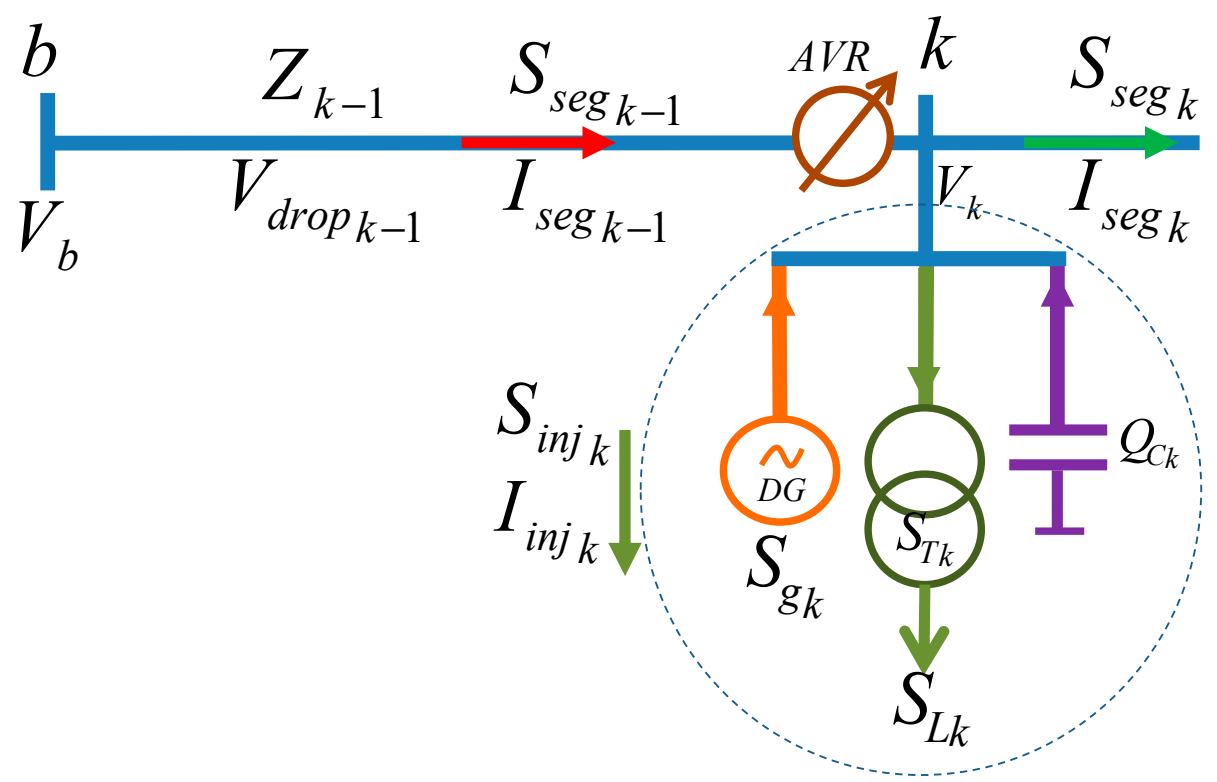

Figure 5. Electric equivalent of an active distribution network (ADN) segment. AVR: automatic voltage regulator; DG: distributed generation. 


\subsection{Modeling of Distribution Line}

The typical $\pi$-model has been generally used to implement the modeling of a distribution line segment connecting two nodes. The series impedance matrix $Z$ of any three-phase line segment is represented as [16]:

$$
Z=l \cdot\left(\begin{array}{lll}
z_{11} & z_{12} & z_{13} \\
z_{21} & z_{22} & z_{23} \\
z_{31} & z_{32} & z_{33}
\end{array}\right)
$$

where $l$ is the segment length. Element $z_{i i}$ along the diagonal of the series impedance matrix is the self-impedance of conductor $i$ per unit length. Element $z_{i j}$ along the off-diagonal is the mutual impedance between conductors $i$ and $j$ per unit length. Equations (2) and (3) use the modified Carson's equations [16] to represent the self and mutual impedances, respectively.

$$
\begin{gathered}
z_{i i}=r_{d}+R_{r e f}\left(1+\alpha\left(T-T_{r e f}\right)\right)+j\left[(2 \pi f)\left(0.2 \times 10^{-3}\right) \ln \left(\frac{D_{e}}{G M R}\right)\right] \\
z_{i j}=r_{d}+j\left[(2 \pi f)\left(0.2 \times 10^{-3}\right) \ln \left(\frac{D_{e}}{G M D}\right)\right]
\end{gathered}
$$

where $r_{d}, \alpha, T$ and $f$ are the resistance of $\operatorname{dirt}$ in $\Omega / \mathrm{km}$, the temperature coefficient of conductor material, the operating temperature in ${ }^{\circ} \mathrm{C}$ and the system frequency in Hertz, respectively. The reference resistance $R_{r e f}$ in $\Omega / \mathrm{km}$ of conductor $i$ is given by the manufacturer at a reference temperature $T_{r e f}=20^{\circ} \mathrm{C}$. The distances $D_{e}, G M R$ and GMD in meters are, respectively, the distance from conductor $i$ to dirt, the geometric mean radius of conductor $i$ and the geometric mean distance between the three conductors. Although the shunt admittance at the distribution voltage level is small enough to be neglected, the model has the flexibility to include that effect.

\subsection{Modeling of Transformer Losses}

A three-phase distribution transformer converts the consumed or generated power at the low-voltage network to the medium voltage network, along with the real and reactive power dissipated by that transformer. The power dissipated inside the distribution transformer shown in Figure 5 is given by [31-33]:

$$
S_{T k}=\left(P_{o}\left(\frac{V_{k}}{V_{r}}\right)^{2}+P_{c} \beta^{2}\left(\frac{V_{r}}{V_{k}}\right)^{2}\right)+j\left(I_{o} S_{r}\left(\frac{V_{k}}{V_{r}}\right)^{2}+U_{x} S_{r} \beta^{2}\left(\frac{V_{r}}{V_{k}}\right)^{2}\right)
$$

where $S_{T k}$ is the apparent power that dissipated inside the transformer, $V_{r}$ is the rated voltage, and $V_{k}$ is the node voltage. $S_{r}$ and $\beta$ are the transformer-rated power and the transformer loading percentage, respectively. $P_{o}, P_{c}$ and $I_{o}$ are the no-load losses, full-load losses and percentage of no-load current, respectively. The parameter $U_{x}$ in Equation (4) represents the reactive part of the percentage short-circuit voltage, which can be expressed as [31-33]:

$$
U_{x}=\sqrt{U_{s}^{2}-\left(\frac{100 P_{c}}{S_{r}}\right)^{2}}
$$

where $U_{s}$ is the percentage of short-circuit voltage given by the transformer manufacturer.

\subsection{Modeling of $A V R$}

AVR is a normal auto-transformer equipped with an automatic tap-changing mechanism [34-39]. Standard AVR provides $\pm 10 \%$ voltage regulation in 32 steps of approximately $5 / 8 \%$ each. The tap of maximum raise position is $16 \mathrm{R}$, while $16 \mathrm{~L}$ is the tap of minimum lower position. The AVR has an automatic tap-changer able to switch from $16 \mathrm{R}$ to $16 \mathrm{~L}$ and vice versa in less than $10 \mathrm{~s}$. 
According to the IEEE Std. C57.15-2009 (IEC60076-21:2011) standard [36], AVR is manufactured in one of two types: ANSI type-A and ANSI type-B. Figure 6 shows the overall functional diagram of a single-phase type-A regulator unit. Commonly, distribution utilities prefer to use three individual single-phase regulators rather than a single compact three-phase unit because the practical unbalance in voltage requires controlling each phase individually. The presence of more than one winding inside the same tank raises the winding and oil temperature, which means more losses. Additionally, the size of a single-phase AVR unit is much smaller as compared to a compact three-phase unit; this facilitates the processes of transportation, installation and maintenance. Moreover, in case of damage or fault in a single-phase AVR unit, the remaining two units can be reconnected as an open-delta configuration to continue voltage regulation during the period of repairing or replacing the damaged unit.

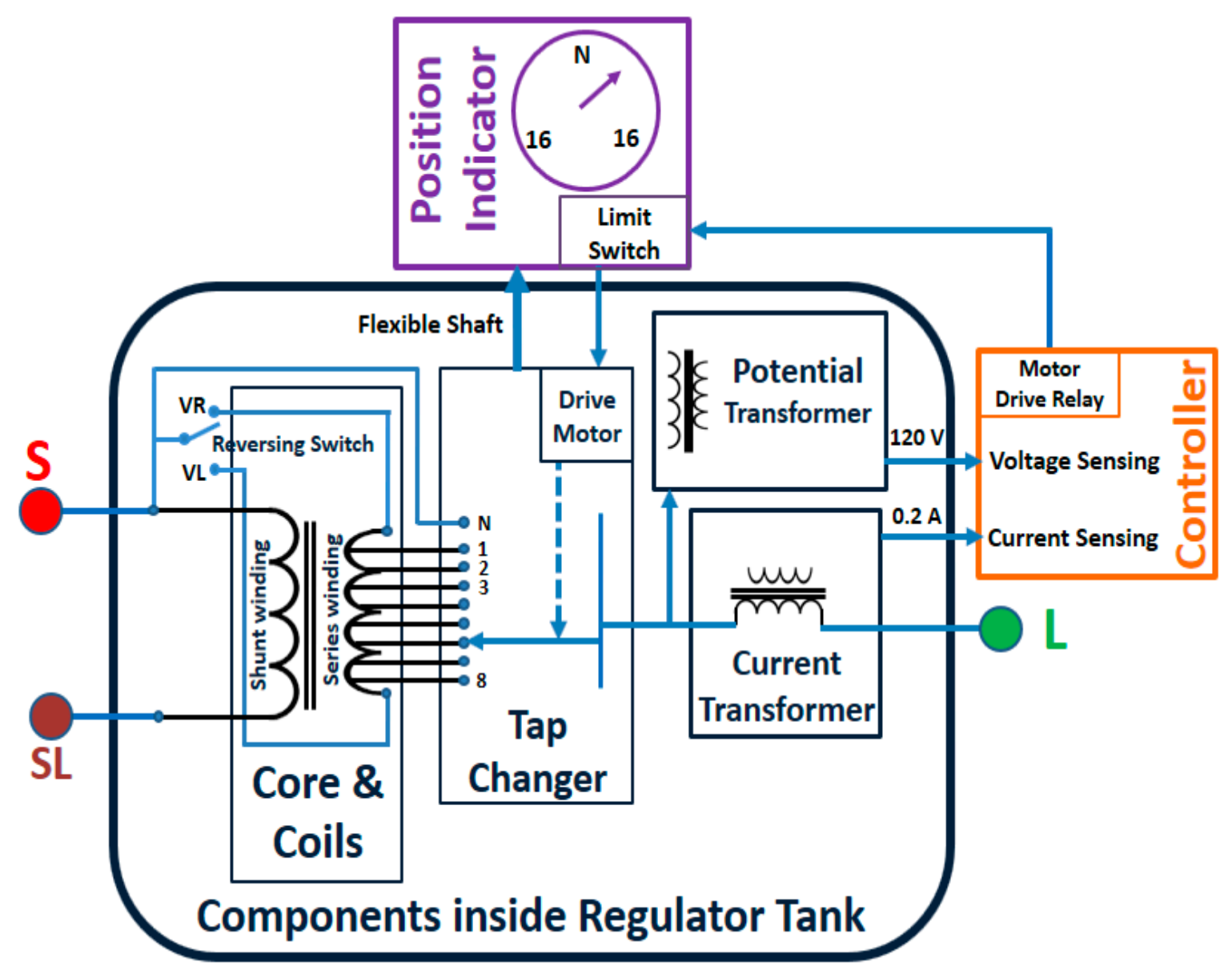

Figure 6. Overall functional diagram of the AVR.

Since the common configuration of a primary DN is delta, single-phase AVR units are typically grouped in one of two connections [16]: closed-delta or open-delta. Figure 7 shows the closed-delta connection where three single-phase units are required to provide up to $15 \%$ voltage regulation. In an open-delta connection, only two units can be used to provide up to $10 \%$ voltage regulation as illustrated in Figure 8. 


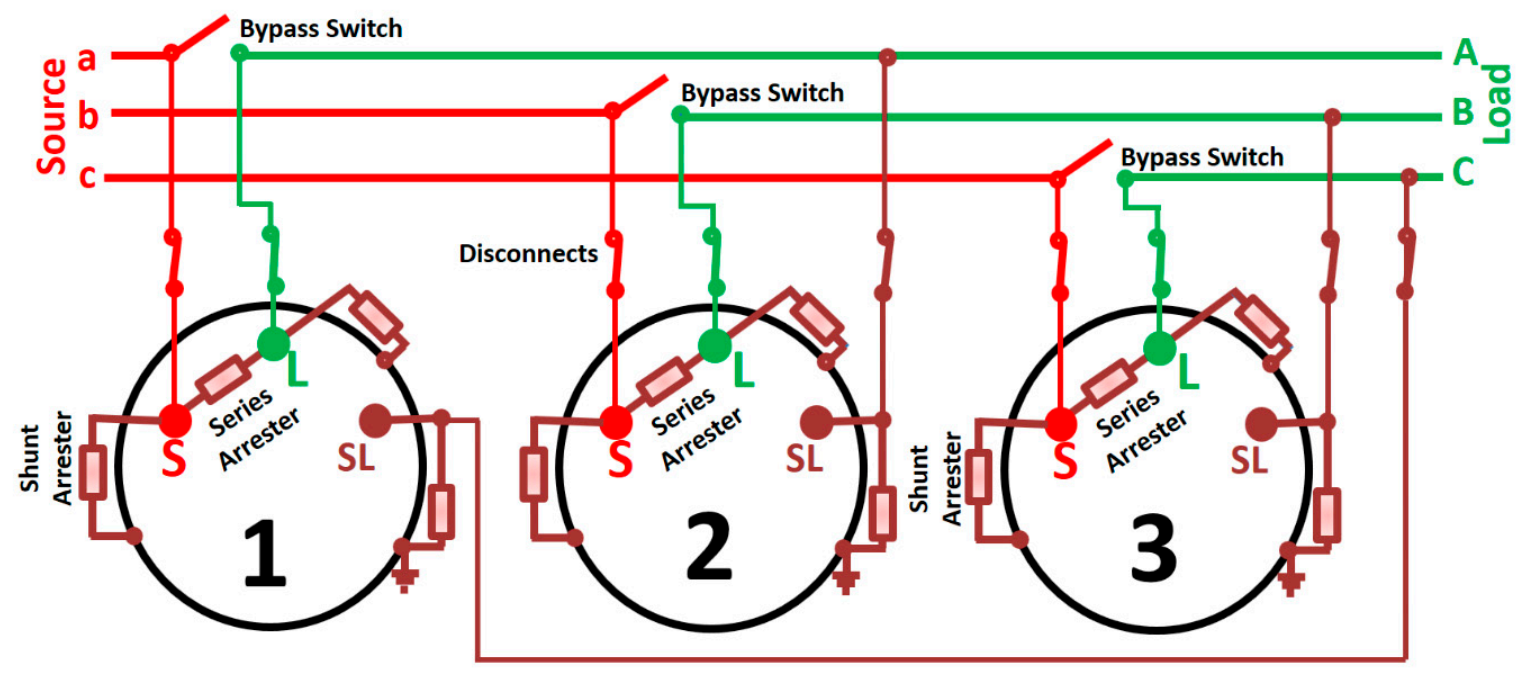

Figure 7. Closed-delta connection of AVR units.

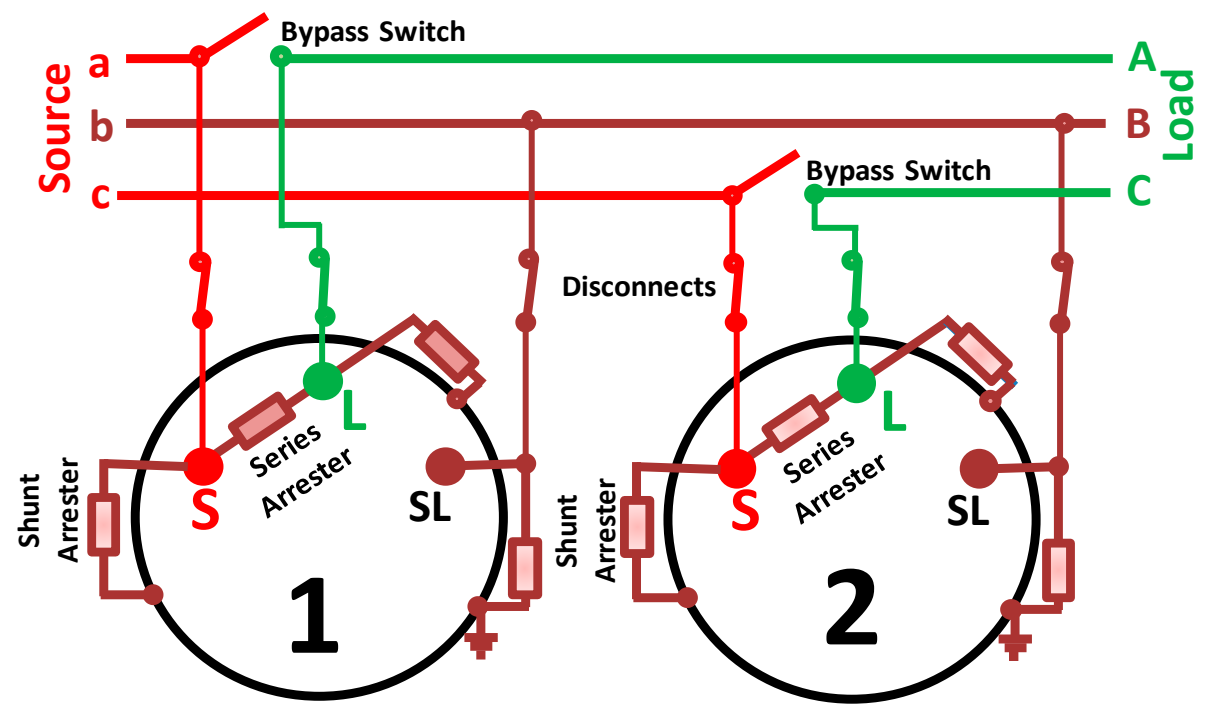

Figure 8. Open-delta connection of AVR units.

The relationship between the source voltage and current $\left(V_{\text {Source }}\right.$ and $\left.I_{\text {Source }}\right)$ to the load voltage and current $\left(V_{\text {Load }}\right.$ and $\left.I_{\text {Load }}\right)$ are governed by [16,37-39]:

For Type-A Regulator:

$$
V_{\text {Source }}=\frac{1}{a_{R}} \cdot V_{\text {Load }}, I_{\text {Sou }}=a_{R} \cdot I_{\text {Load }}
$$

where

$$
a_{R}=\left\{\begin{array}{l}
1+N_{R} \cdot \text { Tap for raise taps } \\
1-N_{R} \cdot \text { Tap for lower taps }
\end{array}\right.
$$

For Type-B Regulator:

$$
V_{\text {Source }}=a_{R} \cdot V_{\text {Load }}, I_{\text {Source }}=\frac{1}{a_{R}} \cdot I_{\text {Load }}
$$

where

$$
a_{R}=\left\{\begin{array}{c}
1-N_{R} \cdot \text { Tap for raise taps } \\
1+N_{R} \cdot \text { Tap for lower taps }
\end{array}\right.
$$


In Equations (7) and (9), $N_{R}$ is the per unit regulation of single step $\left(N_{R}=0.00625\right.$ for a step-type AVRs), and Tap is the tap position of the current step.

\subsection{Modeling of DG Unit}

DG is a relatively small power generator directly connected to the DN owned by the distribution system operator (DSO) or connected at the customer side beyond the point of common coupling. DG unit can be one of the following types [40]: (1) photo-voltaic system, (2) wind turbine, (3) fuel cell, (4) gas turbine, (5) internal combustion engine or (6) micro-turbine. Regarding their power production, DG units are classified into four types: (1) Type-I produces real power only; (2) Type-II produces reactive power only; (3) Type-III produces both real and reactive power; and (4) Type-IV produces real power but consumes reactive power.

Regarding their modeling, DG units can be connected to power systems by one of four models [40-43]: (1) constant power factor model connected as PQ-node; (2) constant voltage model connected as PV-node; (3) P model; or (4) PQV model. The commonly used model at the distribution level is the constant power factor model because the DG units have a small capacity, which is insufficient to affect the voltage at the point of connection.

In the case of the constant power factor model, the DG unit is characterized by two main parameters. The first parameter is the real part of the generated power $P_{g k}$, and the second is the targeted power factor $P F_{g k}$. For the DG shown in Figure 5, the apparent power $S_{g k}$ generated at node $k$ can be expressed as [41]:

$$
S_{g k}=P_{g k}\left(1+j \sqrt{P F_{g k}^{-2}-1}\right)
$$

The power generated by a DG unit of that type is typically treated as a negative load injecting current to the network instead of drawing current from the network. Therefore, this point of connection can be considered as a PQ node.

\subsection{Modeling of Shunt Capacitor Bank}

Shunt capacitors are used in DNs to supply a part of the reactive power demands [44]. Therefore, the shunt capacitor bank (SCB) can be considered as a DG unit that generates only reactive power. The benefits of reactive power compensation in DNs using SCBs are power factor correction, voltage drop reduction, power loss reduction, system capacity release and power quality improvement.

SCB can be modeled as a delta-connected load of constant impedance. The effective reactive power of the $\mathrm{SCB}$ is proportional to the square value of voltage magnitude at the point of connection. For an SCB of rated reactive power $Q_{r k}$ at rated voltage $V_{r}$, its effective reactive power $Q_{C k}$ when connected to node $k$ is calculated by [41]:

$$
Q_{C k}=Q_{r k}\left|\frac{V_{k}}{V_{r}}\right|^{2}
$$

\subsection{Load Models}

The majority of the distribution power demands are domestic, industrial or commercial loads. The power consumed by these types of loads may vary according to voltage or frequency deviations from their rated values. As attention is focused here on the static analysis, only the voltage effects are considered, and the frequency effects may be neglected. Owing to their voltage dependence, distribution loads can be one or a mix of three models: (1) constant power (CP) model, in which the power consumed by the load does not depend on voltage changes; (2) constant current (CC) model, where the power consumed varies directly with voltage magnitudes; and (3) constant impedance (CI) model, in which the power consumed by the load varies directly with the square of voltage magnitudes. 
The power dependency of a certain load to voltage changes can be expressed in a general exponential form as [45]:

$$
S_{L k}=S_{r k}\left(\frac{V_{k}}{V_{r}}\right)^{n}
$$

where $S_{L k}$ is the consumed apparent power, $V_{k}$ is the node voltage, $S_{r k}$ is the rated apparent power of the load, $V_{r}$ is the rated voltage, and $n$ is the model exponent. By setting $n$ to 0,1 or 2 , the load type can be turned into CP, CC or CI, respectively [45].

\section{Proposed Power-Flow Algorithm}

To describe the proposed power-flow algorithm, a general scheme of a three-phase distribution network is considered. The network is assumed to contain a total number of nodes $N_{n}$ and segments $N_{s}$. Typically, $N_{s}=N_{n}-1$ for radial DNs. The voltage $V_{1}$ at the slack node 1 (main substation) is generally taken as a base voltage. All other successive nodes are sequentially numbered. Figure 9 illustrates the program flow-chart. As shown, the algorithm consists of four modules: initialization, matrices construction, BFS iterations and losses calculations. The following subsections describe the algorithm sequence.

\subsection{Module 1: Initialization}

- Input the network data (specifications and locations of the network components).

- Input the loads data (locations, consumptions and types of all load points).

- Select the solution accuracy $(\varepsilon)$ and the maximum number of iterations (max_itr).

- Recall the required parameters related to network components from the database library.

\subsection{Module 2: Matrices Construction}

- Construct the connection matrix (CONMAT) [30], the series impedance matrix (Z) and the shunt admittance matrix $(Y)$.

\subsection{Module 3: BFS Iterations}

- Calculate the power injected at each node $S_{i n j}$ assuming a flat voltage profile. $S_{i n j}$ is the resultant of the load apparent power $S_{L}$ (Equation (12)), the transformer dissipated power $S_{T}$ (Equation (4)), the apparent power generated by DG unit $S_{g}$ (Equation (10)) and the effective reactive power of capacitor bank $Q_{C}$ (Equation (11)) if any.

- $\quad$ Repeat the following BFS iterations:

\subsubsection{Backward Sweep Calculations:}

- $\quad$ Correct $S_{i n j}$ considering the load models, DG, SCB and transformer losses.

- Find the current injected to each node using: $I_{i n j}=\left(S_{i n j} / V\right)^{*}$.

- Find the current flowed through each segment using: $I_{\text {seg }}=[C O N M A T]\left[I_{i n j}\right]$.

- Find the voltage drop across each segment using: $V_{\text {drop }}=\left[I_{\text {seg }}\right][Z]$.

- Denote the calculated voltage distribution matrix $V$ of the current iteration as $V_{\text {old }}$. 


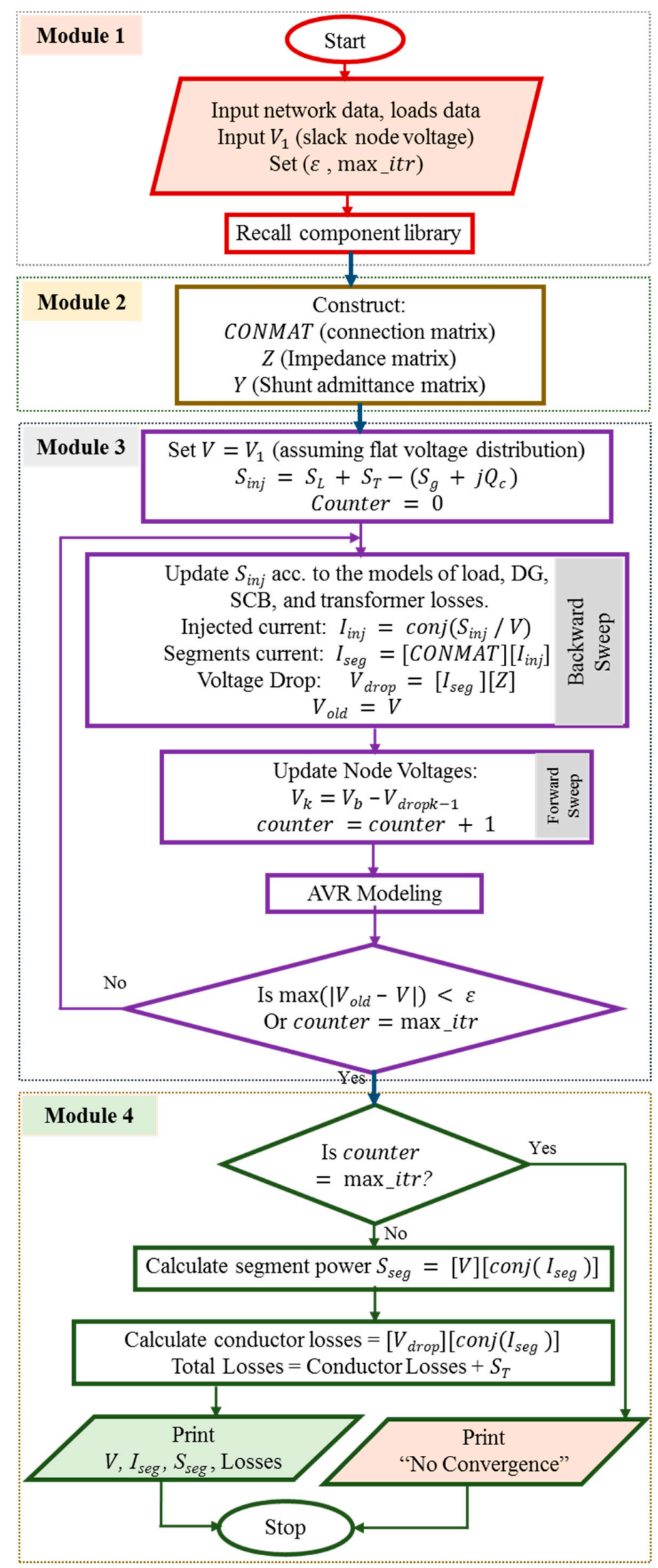

Figure 9. Flow-chart of the power-flow algorithm. SCB: shunt capacitor bank. 


\subsubsection{Forward Sweep Calculations}

- Update the matrix $V$ according to the voltage drop $V_{\text {drop }}$ formerly determined in the backward sweep. Considering the voltage at any arbitrary node $\mathrm{k}\left(V_{k}\right.$ shown in Figure 5$)$ is the voltage at its predecessor node $\mathrm{b}\left(V_{b}\right)$ minus the voltage drop across the segment connecting them $\left(V_{\text {dropk-1 }}\right)$.

- Recalculate both voltage and current matrices according to the AVR model.

- Update the loop counter.

- Terminate the loop if each element in the matrix $\left(V_{\text {old }}-V\right)$ is less than the solution accuracy $\varepsilon$, or the loop counter exceeds the maximum number of iterations (max_itr).

\subsection{Module 4: Losses Calculations}

- $\quad$ Find the power flowed through each segment using: $S_{\text {seg }}=[V]\left[I_{\text {seg }}\right]^{*}$

- Find the conductor losses using $\left[V_{\text {drop }}\right]\left[I_{\text {seg }}\right]^{*}$

- Find the total losses by adding the conductor losses to the transformer losses.

- Print the outputs.

\section{Simulation Results and Discussions}

\subsection{Case I: Unbalanced IEEE 37-Node Feeder}

The unbalanced IEEE 37-node standard feeder is a PDN prepared to evaluate and benchmark distribution system models [46]. The proposed algorithm was applied first to this test feeder in its original PDN state. The algorithm was coded under MATLAB platform version R2016b. A laptop with an Intel (core i5 $2.9 \mathrm{GHz}$ ) processing unit and 4 GB RAM was used to execute the algorithm. The execution time was $0.19 \mathrm{~s}$. Table 2 presents the obtained results. Our results were found to be very close to the results published in [46]. By selecting a solution tolerance $\varepsilon$ equals $10^{-6}$, the maximum founded deviation in the voltage magnitudes as compared to those given in [46] is less than $0.006 \%$. The maximum deviation of the calculated power losses from those of [46] is less than $0.005 \%$. This test asserted the effectiveness of the presented algorithm to analyze unbalanced DNs.

Table 2. Voltage behavior of the ADN as compared to the passive distribution network (PDN) in case I.

\begin{tabular}{cccccccc}
\hline \multicolumn{2}{c}{ Network } & \multicolumn{3}{c}{ PDN } & \multicolumn{3}{c}{ ADN } \\
\hline \multicolumn{2}{c}{ Line-to-line } & A-to-B & B-to-C & C-to-A & A-to-B & B-to-C & C-to-A \\
\hline \multirow{2}{*}{ Min. Voltage } & $(\mathrm{pu})$ & 0.998 & 0.995 & 0.985 & 1.006 & 1.002 & 0.999 \\
\cline { 2 - 8 } & at Node & 741 & 722 & 741 & 741 & 722 & 741 \\
\hline \multirow{2}{*}{ Max. Voltage } & $(\mathrm{pu})$ & 1.044 & 1.025 & 1.035 & 1.031 & 1.019 & 1.025 \\
\cline { 2 - 8 } & at Node & 701 & 701 & 701 & 701 & 701 & 701 \\
\hline \multicolumn{2}{c}{ Tap of AVR } & $7 \mathrm{R}$ & $4 \mathrm{R}$ & - & $5 \mathrm{R}$ & $3 \mathrm{R}$ & - \\
\hline
\end{tabular}

To convert this test system to an ADN, the network was divided into three zones. Each zone has a local area control center (LACC) to monitor and control the corresponding area. Each zone is supposed to have a constant power factor DG unit of type-III. The three DG units were assumed to have the same rated active power of $500 \mathrm{~kW}$ at 0.958 power factor for each. The DG units were located at nodes 720, 744 and 734. Figure 10 compares the line-to-line voltage profile along with the PDN nodes to that along with the ADN nodes. As shown, the conversion to ADN improves voltage unbalance. The shape of the voltage profile also appears to become more flattened in the case of the ADN. 


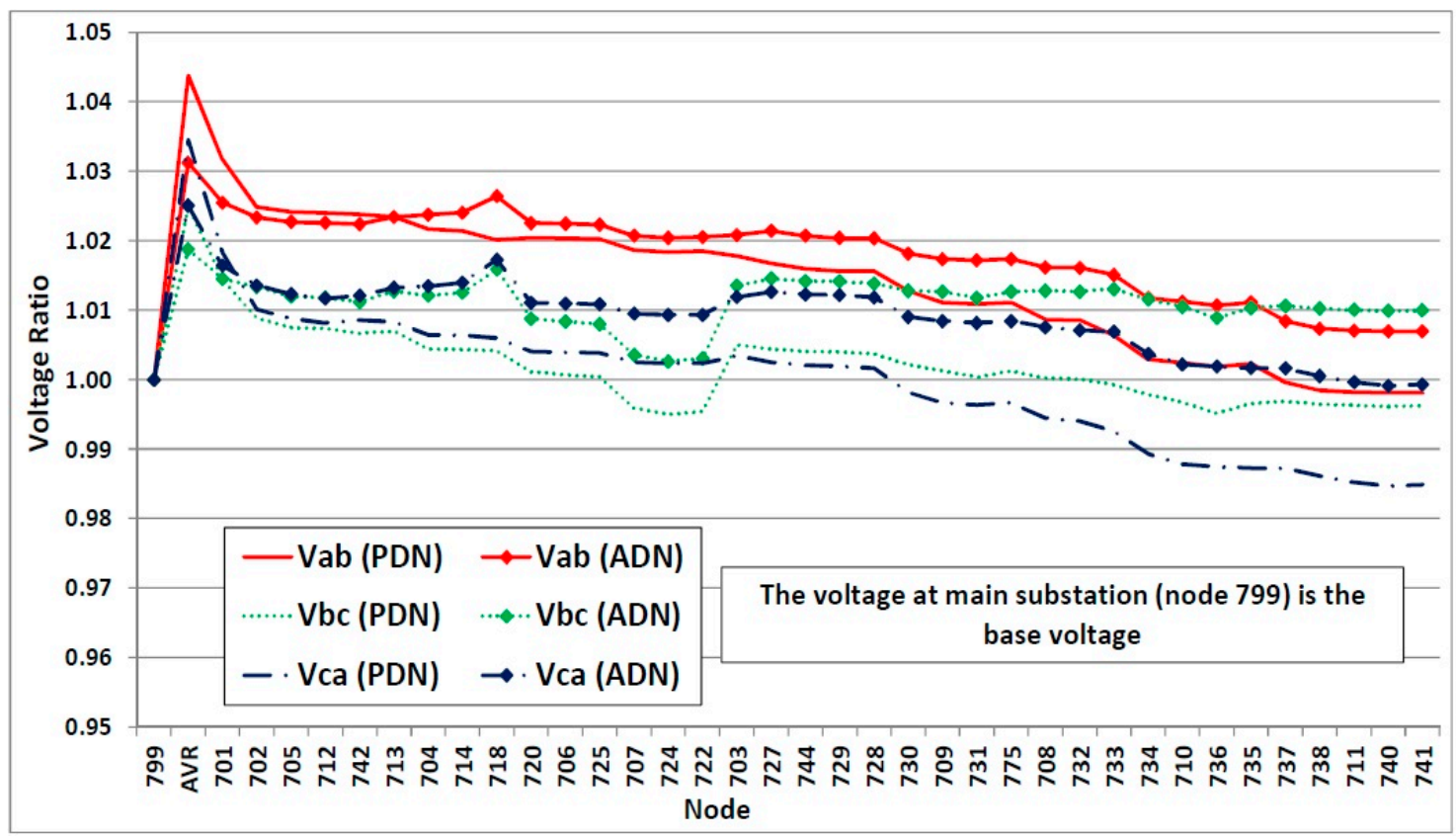

Figure 10. Voltage profile comparison between the ADN and PDN in case I.

Table 2 confirms the same results and clarifies how the conversion to ADN preserves the AVR. As concluded from Table 3, the conversion to ADN greatly reduces the overall network loss to become less than $30 \%$ of its previous PDN value.

Table 3. Losses of the ADN as compared to the PDN in case I.

\begin{tabular}{ccccccccc}
\hline Network & \multicolumn{4}{c}{ PDN } & \multicolumn{4}{c}{ ADN } \\
\hline Line & A & B & C & Total & A & B & C & Total \\
\hline Losses $(\mathrm{kW})$ & 26.669 & 13.804 & 20.087 & 60.560 & 8.118 & 4.076 & 5.918 & 18.112 \\
\hline
\end{tabular}

\subsection{Case II: Balanced UEDN Network}

Figure 11 shows the single line diagram of a $22 \mathrm{kV}$ PDN located at the western desert of Upper Egypt as explained in Section 2. This network is dedicated to supplying an agriculture load at a location far from the nearest power source by more than $100 \mathrm{~km}$. The load consists of 39 electric pumps. Each pump raises water from a deep well to irrigate a farm. The maximum power demand of this area was insufficient to construct a new power station there. Therefore, the DSO was forced to extend that long PDN.

As shown in Figure 11, the UEDN has two groups of AVRs placed at node 4 and node 11. The two AVR groups have the technical data listed in Table 4. Detailed network data and solution variables are listed in the Appendix A. The electrical loads of this network are symmetrical and identical. Each load point feeds a three-phase pump of $88 \mathrm{kVA}$ at 0.9 power factor (PF). Each pump is supplied through a transformer of $20 / 0.4 \mathrm{kV}$ transformation ratio and $300 \mathrm{kVA}$ rated power. The transformer has a tap-changer to select between seven steps manually: two steps to reduce the output voltage, one step for a neutral position without any voltage regulation and four steps to raise the output voltage. The tap-changer is designed to achieve voltage regulation in the output voltage equal to $2.5 \%$ of the input voltage. The average voltage magnitude measured at node 1 (Kharja substation) during the day-time equals $21.5 \mathrm{kV}$. During the night-time, the same average equals $22.5 \mathrm{kV}$. A power quality analyzer device (model HIOKI 3196) was used to measure and record different electrical parameters at node 12 that is about $103.3 \mathrm{~km}$ from the Kharja substation. All measurements were recorded for $72 \mathrm{~h}$ with an interval of 5 min between successive records. Figure 12 displays the load profile during $24 \mathrm{~h}$ measured at node 12 . The displayed profile repeats daily. 


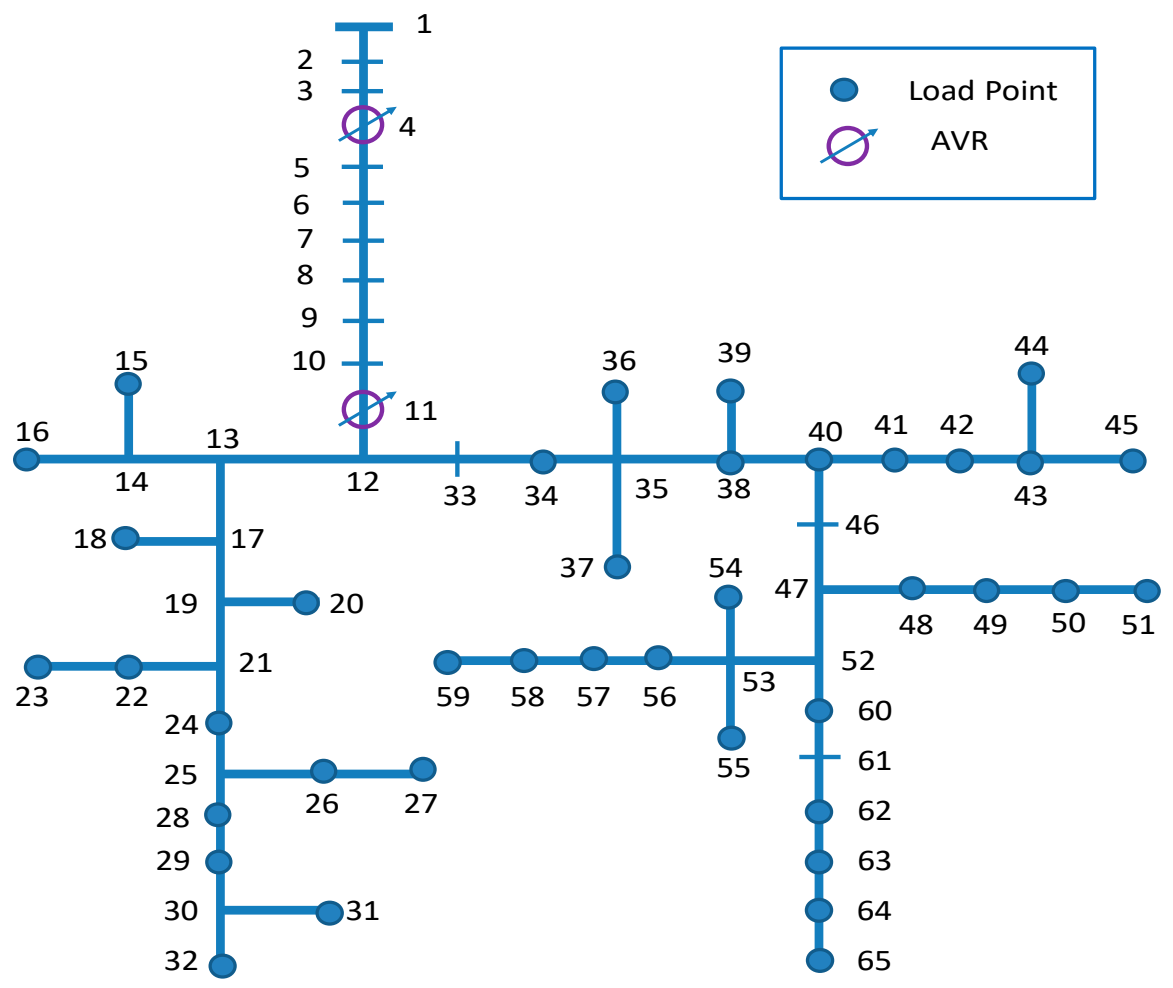

Figure 11. Single-line diagram of the UEDN.

Table 4. Specifications and sittings of the AVR groups in the Upper Egypt distribution network (UEDN).

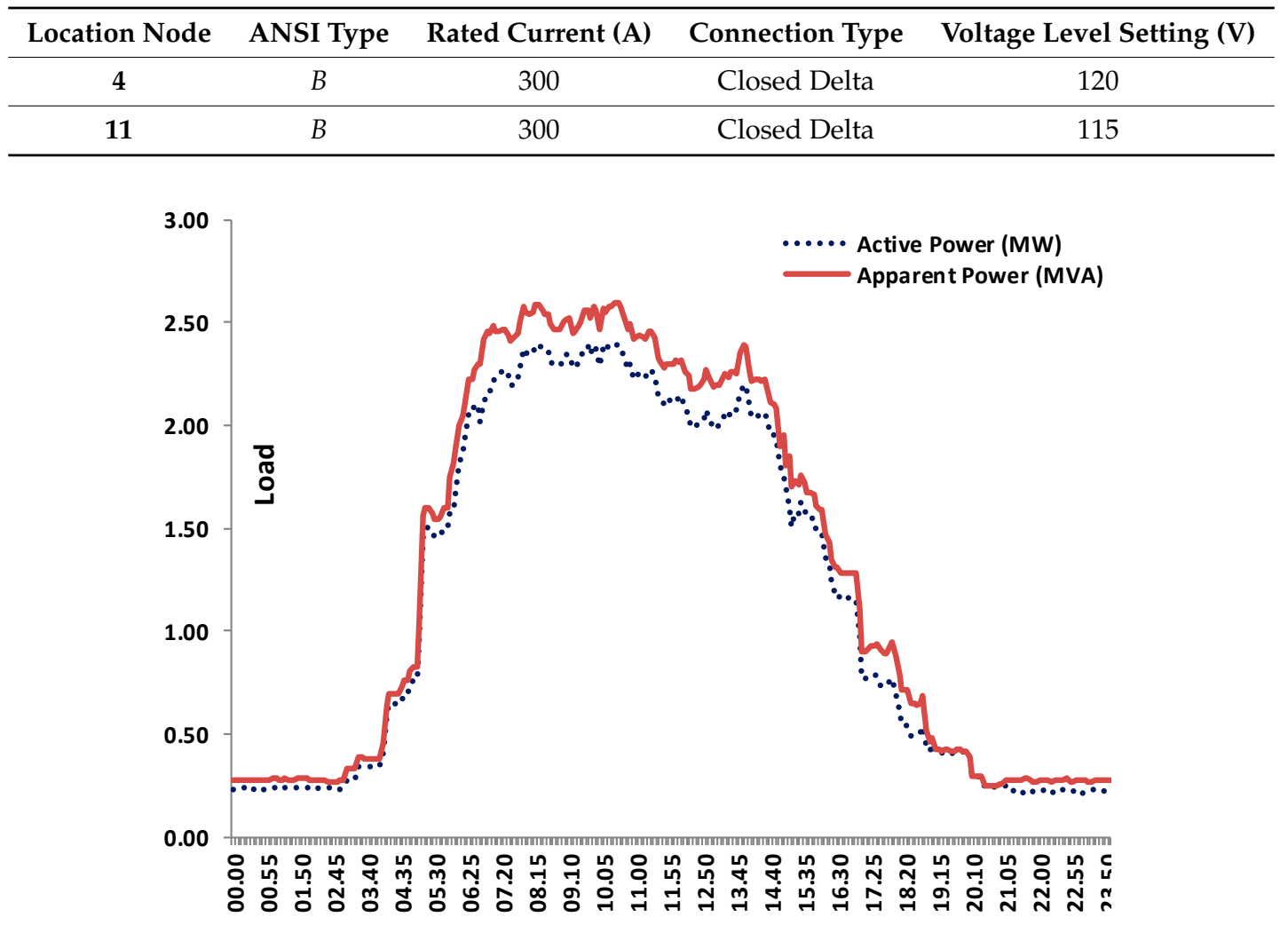

Hour

Figure 12. Daily load profile of the UEDN measured at node 12. 


\subsubsection{PDN Performance}

The passive form of the UEDN is analyzed under two operating modes: the day-time mode and the night-time mode, as follows:

\section{(a) Day-time Mode}

During the day-time, irrigation pumps draw their maximum rated power. At that time, the voltage magnitude at the Kharja substation is $21.5 \mathrm{kV}$. The output results confirm that the two voltage regulators operate at tap 16R. However, some pumps suffer from the operation below their permissible voltage limit. Therefore, these loads draw currents more than their rated values. This operation condition leads to an increase in power losses and reduces the motor lifetime. The minimum voltage magnitude calculated at node 65 equals $18.2 \mathrm{kV}$. The percentage of voltage regulation equals $17.4 \%$, which exceeds the allowable operating limits. The load at node 63 is found to operate in a critical condition. Its calculated voltage equals $364 \mathrm{~V}$ ( $9 \%$ below its rated value). The calculated power losses equal 1.337 MW, i.e., $29.74 \%$ of the total supplied real power are losses.

\section{(b) Night-time Mode}

During the night-time, loads vanish. The only flowed power is the losses resulted from unloaded transformers in-service. At that time, the voltage at the Kharja substation is $22.5 \mathrm{kV}$ which is higher than its rated value. Therefore, the calculated results confirm that the voltage regulator located at node 4 operates at step 3L while the other regulator located at node 11 operates at step $4 \mathrm{~L}$. This operational status of the two AVR groups maintains the voltage magnitudes at essential safe values. The calculated power losses equal $23.6 \mathrm{~kW}$, i.e., all the supplied real power are losses.

\subsubsection{ADN Performance}

To convert the passive UEDN to an ADN, the network was divided into three zones. (1) The first zone extends from node 1 to node 12 without load points; hence, there is no need to install DG units or LACCs in this zone. (2) The second zone is the Max area, which extends from node 13 to node 32 and contains 13 load points. Therefore, it is useful to install a DG unit and LACC at the zone center, node 21. (3) The third zone is the Arbien area, which extends from node 33 to node 65 and contains 26 load points. A suggested DG unit and LACC is required at the zone center, node 46 . Rates and types of the suggested DG units are given in Table 5.

Table 5. Required DG units to turn the passive UEDN into an ADN.

\begin{tabular}{cccc}
\hline $\begin{array}{c}\text { Location } \\
\text { (at Node) }\end{array}$ & $\begin{array}{c}\text { DG } \\
\text { Type }\end{array}$ & Rated Active Power (kW) & Specified Power Factor \\
\hline $\mathbf{2 1}$ & $I I I, P Q$ & 900 & 0.9 \\
\hline $\mathbf{4 6}$ & $I I I, P Q$ & 1800 & 0.9 \\
\hline
\end{tabular}

Because of the following reasons, it is highly recommended to select the DG units as on-grid solar power stations:

- The daily repeated load profile, shown in Figure 12, is similar to the solar power irradiance curve [47]; load vanishes by sunset and returns by sunshine.

- The required lands to construct solar power stations are available.

- The annual mean insolation [48] is high at the case study location as explained in Section 2.

The conversion of the UEDN from a PDN to an ADN improves the overall behavior of the network as concluded from Table 6. This improvement is noticed in the total losses reduction, the voltage 
correction and the convenient operation of AVR groups. Figure 13 confirms the reduction in the total network losses from 1.34 MW (29.74\% of the total consumed power in the PDN) to $85.3 \mathrm{~kW}(2.63 \%$ of the total consumed power in the ADN). This reduction is mainly due to the great reduction in conductors' losses while the transformers' losses remain the same.

Table 6. ADN performance as compared to the PDN in the UEDN under different loading conditions.

\begin{tabular}{cccccc}
\hline \multicolumn{2}{c}{ Network } & \multicolumn{2}{c}{ PDN } & \multicolumn{2}{c}{ ADN } \\
\hline \multirow{2}{*}{ Operation Mode } & $\begin{array}{c}\text { Day-Time } \\
\text { (Full Load) }\end{array}$ & $\begin{array}{c}\text { Night-Time } \\
\text { (No Load) }\end{array}$ & $\begin{array}{c}\text { Day-Time } \\
\text { (Full Load) }\end{array}$ & $\begin{array}{c}\text { Night-Time } \\
\text { (No Load) }\end{array}$ \\
\hline Substation Voltage $(\mathbf{k V})$ & 21.5 & 22.5 & 21.5 & 22.5 \\
\hline \multirow{2}{*}{ Min. Load Voltage } & Magnitude $(\mathbf{k V})$ & 18.17 & 20.83 & 20.65 & 20.83 \\
\cline { 2 - 6 } & Location Node & 65 & 65 & 65 & 65 \\
\hline \multirow{2}{*}{ Max. Load Voltage } & Magnitude $(\mathbf{k V})$ & 19.14 & 20.86 & 20.99 & 20.86 \\
\cline { 2 - 6 } & Location Node & 15 & 15 & 18 & 15 \\
\hline \multirow{2}{*}{ Conductors' Losses } & $\mathbf{k W}$ & 1301.3 & 1.2 & 50.1 & 1.2 \\
\cline { 2 - 6 } & $\mathbf{\%}$ & 28.95 & 4.97 & 1.55 & 4.97 \\
\hline \multirow{2}{*}{ Transformers' losses } & $\mathbf{k W}$ & 35.28 & 22.46 & 35.28 & 22.46 \\
\cline { 2 - 6 } & $\mathbf{\%}$ & 0.79 & 95.03 & 1.10 & 95.03 \\
\hline \multirow{2}{*}{ Total Losses } & $\mathbf{k W}$ & 1336.7 & 23.65 & 85.33 & 23.65 \\
\cline { 2 - 6 } & $\%$ & 29.74 & 100 & 2.63 & 100 \\
\hline Tap Position of AVR at node 4 & $16 \mathrm{R}$ & $3 \mathrm{~L}$ & $7 \mathrm{R}$ & $3 \mathrm{~L}$ \\
\hline Tap Position of AVR at node 11 & $16 \mathrm{R}$ & $4 \mathrm{~L}$ & $3 \mathrm{~L}$ & $4 \mathrm{~L}$ \\
\hline
\end{tabular}

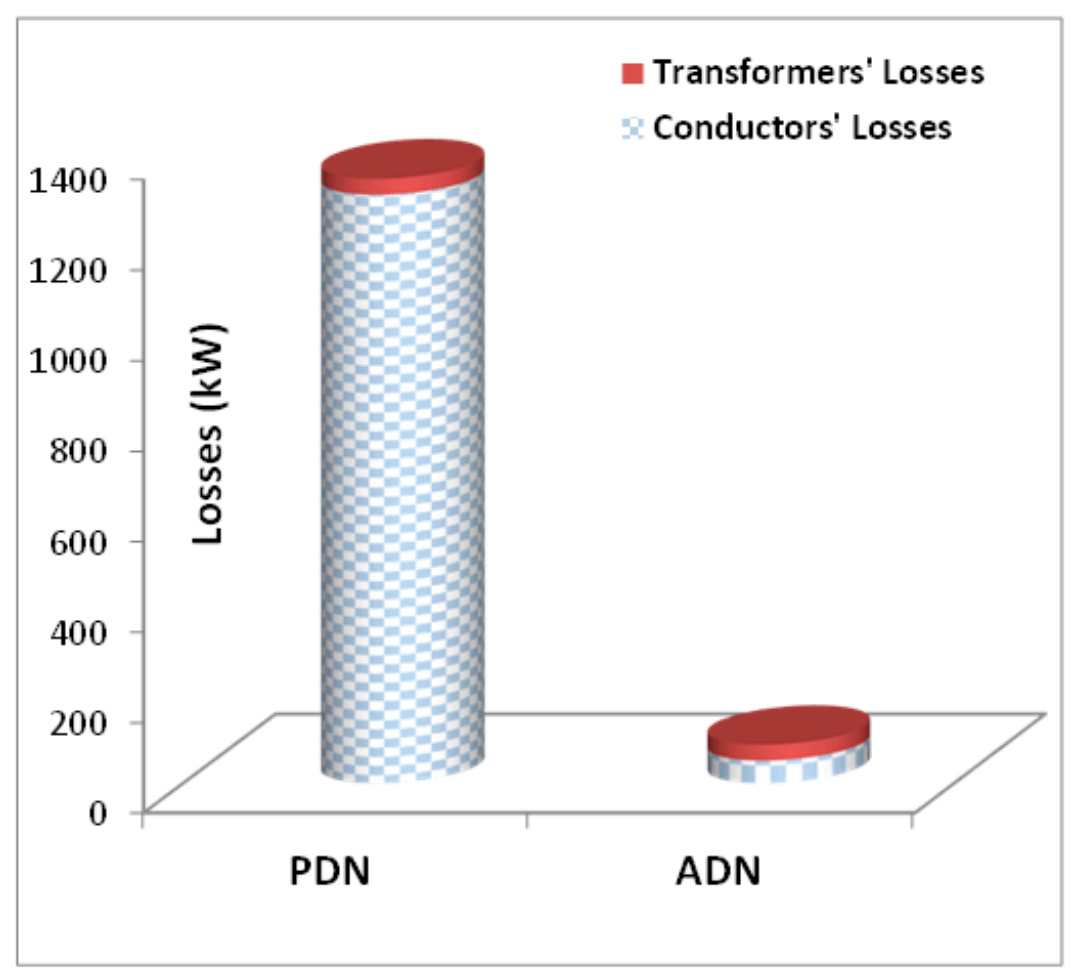

Figure 13. Losses reduction by converting the UEDN from a PDN to an ADN.

Figure 14 compares the voltage profile along the ADN length to that of the PDN during different operating modes. As shown, the ADN moves the operating voltage at load points from a near-critical 
limit $(18 \mathrm{kV})$ to a safe operation state $(21 \mathrm{kV})$. It is also clear that the ADN narrows the wide gap between day-time and night-time voltage profiles. Narrowing this gap removes the daily repeated thermal and electrical stresses on network insulations. Obviously, the ADN also decreases the daily-accumulated number of AVR steps. Therefore, the ADN leads to the convenient operation of AVR groups and extends the AVR lifetime.

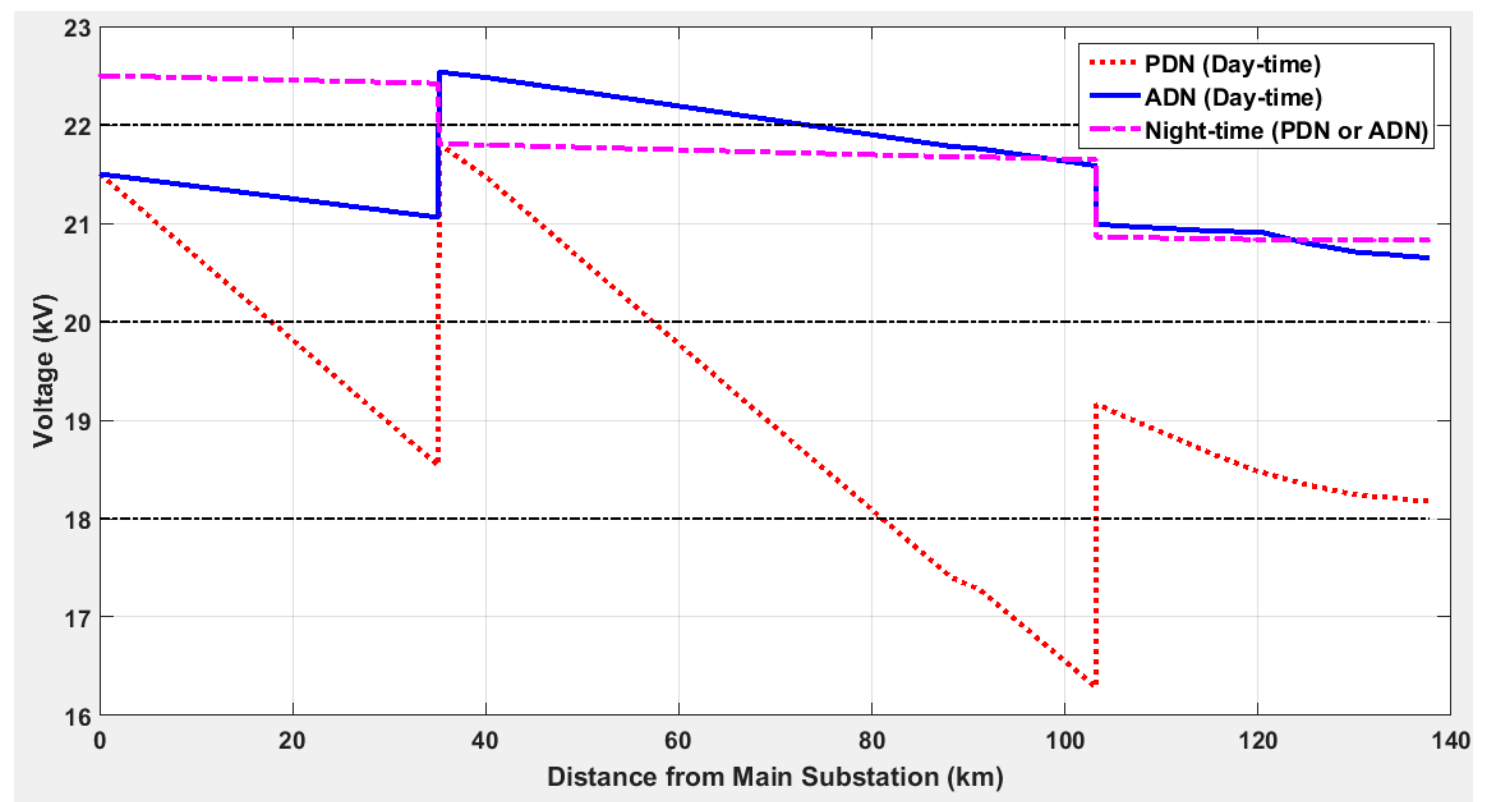

Figure 14. Voltage profile along the UEDN as an ADN compared to PDN under different loading conditions.

The algorithm presented in this paper considers only one DG model-the constant power factor model. Modeling other DG types is planned to be covered in future work. In addition, our future work will include harmonic effects and sub-transient network states.

\section{Conclusions}

A new algorithm for power-flow calculations based on the BFS method was developed in this paper. Modeling of the commonly used medium voltage components including distribution line, AVR, DG unit and SCB was presented. Moreover, different load models and the power dissipated inside distribution transformers were also considered. The proposed models were integrated with the developed power-flow algorithm to form a comprehensive tool valid to simulate balanced or unbalanced ADNs. The proposed algorithm was tested on the standard IEEE 37-node feeder as an unbalanced network. The validation test confirmed the effectiveness of the presented algorithm to simulate unbalanced DNs. A remote PDN located in the western desert of Upper Egypt was highlighted as a practical balanced application of the proposed algorithm. The examined situation of the Egyptian electricity sector imposes the need to increase the future contribution of renewable energies. The passive $22 \mathrm{kV}$ UEDN is suggested to be turned into an ADN by the installation of two DG units with two LACCs. The conversion of the UEDN from a PDN to an ADN improves the overall behavior of the network. The total network losses are reduced from $1.34 \mathrm{MW}(29.74 \%$ of the total consumed power in the PDN) to $85.3 \mathrm{~kW}$ (2.63\% of the total consumed power in the ADN). ADN moves the operating voltage at load points from a near-critical limit $(18 \mathrm{kV})$ to a safe operation state $(21 \mathrm{kV})$. $\mathrm{ADN}$ also narrows the wide gap between day-time and night-time voltage profiles which removes the daily repeated thermal and electrical stresses on network insulations. Moreover, ADN decreases the daily-accumulated number of AVR steps. This leads to the convenient operation of AVR groups and extends the AVR lifetime. 
Author Contributions: Conceptualization, A.A.R., A.A.Z.D. and A.-H.M.E.; methodology, A.A.R., A.A.Z.D. and A.-H.M.E.; software, A.A.R. and A.A.Z.D.; validation, A.A.R., A.A.Z.D. and H.H.A.; formal analysis, A.A.R., A.A.Z.D. and H.H.A.; investigation, P.S. and A.A.Z.D.; resources, H.H.A., P.S. and A.A.Z.D.; data curation, A.A.R., A.A.Z.D. and A.-H.M.E.; writing-original draft preparation, A.A.R., A.A.Z.D. and A.-H.M.E.; writing-review and editing, A.A.R., P.S. and A.A.Z.D.; visualization, A.A.Z.D.; supervision, A.A.Z.D. and A.-H.M.E.; project administration, A.A.Z.D., H.H.A., P.S. and A.-H.M.E.; funding acquisition, H.H.A., P.S. and A.A.Z.D. All authors have read and agreed to the published version of the manuscript.

Funding: This research received no external funding

Conflicts of Interest: The authors declare no conflict of interest.

\section{Appendix A}

Conductor types and lengths of the case II UEDN are given in Table A1. Table A2 presents the solution variables. The required parameters to simulate the underground cables and overhead lines of the UEDN are given in Tables A3 and A4, respectively. Table A5 lists the parameters of the UEDN distribution transformer.

Table A1. Conductor types and conductor lengths of the UEDN.

\begin{tabular}{|c|c|c|c|c|c|c|c|c|c|c|c|}
\hline $\begin{array}{l}\text { From } \\
\text { node }\end{array}$ & $\begin{array}{c}\text { To } \\
\text { node }\end{array}$ & Code $^{a}$ & $\begin{array}{c}\text { Length } \\
(\mathrm{km})\end{array}$ & $\begin{array}{l}\text { From } \\
\text { node }\end{array}$ & $\begin{array}{c}\text { To } \\
\text { node }\end{array}$ & Code $^{a}$ & $\begin{array}{c}\text { Length } \\
(\mathrm{km})\end{array}$ & $\begin{array}{l}\text { From } \\
\text { node }\end{array}$ & $\begin{array}{c}\text { To } \\
\text { node }\end{array}$ & Code $^{a}$ & $\begin{array}{l}\text { Length } \\
(\mathbf{k m})\end{array}$ \\
\hline 01 & 02 & 2401 & 0.1 & 21 & 24 & 1502 & 2 & 40 & 46 & 1502 & 0.5 \\
\hline 02 & 03 & 2403 & 35 & 24 & 25 & 1502 & 3 & 46 & 47 & 1502 & 5 \\
\hline 03 & 04 & 4001 & 0.05 & 25 & 26 & 0702 & 1 & 47 & 48 & 0702 & 0.5 \\
\hline 04 & 05 & 4001 & 0.05 & 26 & 27 & 0702 & 1 & 48 & 49 & 0702 & 0.5 \\
\hline 05 & 06 & 2403 & 5 & 27 & 28 & 0702 & 1 & 49 & 50 & 0702 & 1 \\
\hline 06 & 07 & 1502 & 25 & 28 & 29 & 0702 & 1.5 & 50 & 51 & 0702 & 1 \\
\hline 07 & 08 & 1502 & 23 & 28 & 30 & 0702 & 4 & 47 & 52 & 1502 & 5 \\
\hline 08 & 09 & 2401 & 3 & 25 & 31 & 1502 & 0.5 & 52 & 53 & 0702 & 1 \\
\hline 09 & 10 & 1502 & 12 & 31 & 32 & 1502 & 4 & 53 & 54 & 0702 & 0.2 \\
\hline 10 & 11 & 4001 & 0.05 & 12 & 33 & 2401 & 0.3 & 53 & 55 & 0702 & 0.2 \\
\hline 11 & 12 & 4001 & 0.05 & 33 & 34 & 1502 & 1 & 53 & 56 & 0702 & 1 \\
\hline 12 & 13 & 1502 & 0.5 & 34 & 35 & 1502 & 1 & 56 & 57 & 0702 & 2 \\
\hline 13 & 14 & 1502 & 2.5 & 35 & 36 & 0702 & 0.5 & 57 & 58 & 0702 & 0.5 \\
\hline 14 & 15 & 0701 & 0.1 & 35 & 37 & 0702 & 0.5 & 58 & 59 & 0702 & 0.5 \\
\hline 14 & 16 & 0701 & 0.1 & 35 & 38 & 1502 & 10 & 52 & 60 & 1502 & 2 \\
\hline 13 & 17 & 1502 & 2 & 38 & 39 & 0702 & 2 & 60 & 61 & 1502 & 2 \\
\hline 17 & 18 & 0701 & 0.5 & 38 & 40 & 1502 & 4 & 61 & 62 & 0702 & 1.5 \\
\hline 17 & 19 & 1502 & 1 & 40 & 41 & 0702 & 1 & 62 & 63 & 0702 & 0.3 \\
\hline 19 & 20 & 0702 & 0.3 & 41 & 42 & 0702 & 1 & 63 & 64 & 0702 & 1.5 \\
\hline 19 & 21 & 1502 & 0.5 & 42 & 43 & 0702 & 3 & 64 & 65 & 0702 & 0.3 \\
\hline 21 & 22 & 0702 & 3 & 43 & 44 & 0702 & 0.5 & & & & \\
\hline 22 & 23 & 0702. & 9 & 43 & 45 & 0702 & 1.5 & & & & \\
\hline
\end{tabular}

a Codes 4001, 2401 and 0701 denote three-core aluminum cables of nominal cross-sectional areas of $400 \mathrm{~mm}^{2}$ $240 \mathrm{~mm}^{2}$ and $70 \mathrm{~mm}^{2}$, respectively. Codes 1502 and 0702 denote overhead ACSR of cross-sectional areas of $150 / 25 \mathrm{~mm}^{2}$ and $70 / 12 \mathrm{~mm}^{2}$, respectively. Code 2403 denotes an overhead all aluminum alloy conductor (AAAC) of a cross-sectional area of $240 \mathrm{~mm}^{2}$.

Table A2. Solution variables and UEDN parameters.

\begin{tabular}{ccc}
\hline \multicolumn{3}{c}{ Solution Variables } \\
\hline max_itr & 100 & iterations \\
\hline$\varepsilon$ & $10^{-6}$ & - \\
\hline$f$ & 50 & $\mathrm{~Hz}$ \\
\hline
\end{tabular}


Table A3. Cable parameters of the UEDN.

\begin{tabular}{cc}
\hline Utility Grid (UG) Cable Parameters (Codes 701, 2401 and 4001) \\
\hline Code & $z_{i i}(\Omega / \mathrm{km})$ \\
\hline 0701 & $0.5683+\mathrm{j} 0.11624$ \\
\hline 2401 & $0.1618+\mathrm{j} 0.09676$ \\
\hline 4001 & $0.102+\mathrm{j} 0.090164$ \\
\hline
\end{tabular}

Table A4. Overhead line parameters of the UEDN.

\begin{tabular}{|c|c|c|c|}
\hline \multicolumn{4}{|c|}{ Overhead Transmission Lines (OHTL) Network Parameters (Codes 702, 1502 and 2403) } \\
\hline$T$ & \multicolumn{2}{|c|}{70} & ${ }^{\circ} \mathrm{C}$ \\
\hline$r_{d}$ & \multicolumn{2}{|c|}{0.04935} & $\Omega / \mathrm{km}$ \\
\hline$D_{e}$ & \multicolumn{2}{|c|}{931.76} & $\mathrm{~m}$ \\
\hline GMD & \multicolumn{2}{|c|}{1151.15} & $\mathrm{~mm}$ \\
\hline Code & $R_{r e f}(\Omega / \mathrm{km})$ & GMR $(\mathrm{mm})$ & $\begin{array}{c}\alpha \\
\left(/{ }^{\circ} \mathrm{C}\right)\end{array}$ \\
\hline 0702 & 0.4130 & 4.7502 & \multirow{2}{*}{0.00404} \\
\hline 1502 & 0.1939 & 6.9426 & \\
\hline 2403 & 0.1373 & 7.8358 & 0.00347 \\
\hline
\end{tabular}

Table A5. Parameters of the UEDN distribution transformer.

\begin{tabular}{ccc}
\hline \multicolumn{3}{c}{ Distribution Transformer Parameters } \\
\hline $\boldsymbol{S}_{\boldsymbol{r}}$ & 300 & $\mathrm{kVA}$ \\
\hline $\boldsymbol{P}_{\boldsymbol{o}}$ & 576 & Watt \\
\hline $\boldsymbol{P}_{\boldsymbol{c}}$ & 3815 & Watt \\
\hline $\boldsymbol{U}_{\boldsymbol{s}}$ & 4 & $\%$ \\
\hline
\end{tabular}

\section{References}

1. Dunstan, L.A. Machine computation of power network performance. Trans. Am. Inst. Electr. Eng. 1947, 66, 610-624. [CrossRef]

2. Dunstan, L.A. Digital load flow studies. Trans. Am. Inst. Electr. Eng. III-PAS 1954, 73, 825-832. [CrossRef]

3. Ward, J.; Hale, H. Digital computer solution of power flow problems. Trans. Am. Inst. Electr. Eng. III-PAS 1956, 75, 398-402. [CrossRef]

4. Tinney, W.F.; Hart, C.E. Power flow solution by Newton's method. IEEE Trans. Power Appar. Syst. 1967, 86, 1449-1460. [CrossRef]

5. Stagg, G.W.; El-Abiad, A.H. Computer Methods in Power System Analysis; International Student, Ed.; McGraw Hill Kogakusha Ltd.: Tokyo, Japan; Auckland, New Zealand; Beirut, Liban, 1968.

6. Stott, B. Decoupled Newton load flow. IEEE Trans. Power Appar. Syst. 1972, 91, 1955-1959. [CrossRef]

7. Alsac, O.; Stott, B. Optimal load flow with steady-state security. IEEE Trans. Power Appar. Syst. 1974, 93, 745-751. [CrossRef]

8. Stott, B.; Alsac, O. Fast decoupled load flow. IEEE Trans. Power Appar. Syst. 1974, 93, 859-869. [CrossRef]

9. Kersting, W. A method to teach the design and operation of a distribution system. IEEE Trans. Power Appar. Syst. 1984, 103, 1945-1952. [CrossRef]

10. Cheng, C.S.; Shirmohammadi, D. A three-phase power flow method for real-time distribution system analysis. IEEE Trans. Power Syst. 1995, 10, 671-679. [CrossRef]

11. Teng, J.H. A direct approach for distribution system load flow solutions. IEEE Trans. Power Deliv. 2003, 18, 882-887. [CrossRef] 
12. AlHajri, M.; El-Hawary, M. Exploiting the radial distribution structure in developing a fast and flexible radial power flow for unbalanced three-phase networks. IEEE Trans. Power Deliv. 2010, 25, 378-389. [CrossRef]

13. Hamouda, A.; Zehar, K. Improved algorithm for radial distribution networks load flow solution. Int. J. Electr. Power Energy Syst. 2011, 33, 508-514. [CrossRef]

14. Abul'Wafa, A.R. A network-topology-based load flow for radial distribution networks with composite and exponential load. Electr. Power Syst. Res. 2012, 91, 37-43. [CrossRef]

15. Shakarami, M.; Beiranvand, H.; Beiranvand, A.; Sharifipour, E. A recursive power flow method for radial distribution networks: Analysis, solvability and convergence. Int. J. Electr. Power Energy Syst. 2017, 86, 71-80. [CrossRef]

16. Kersting, W.H. Distribution System Modeling and Analysis, 4th ed.; CRC Press Taylor \& Francis Group: Boca Raton, FL, USA, 2017; ISBN 978-1-3151-20782.

17. Jayamohan, M.; Drisya, K.; Bindumol, E.; Babu, C. Improved BFSA for computation of power loss and voltage profile in radial distribution system. In Proceedings of the IEEE International Conference on Electrical, Electronics, and Optimization Techniques ICEEOT, Tamil Nadu, India, 3-5 March 2016; pp. 3247-3250. [CrossRef]

18. Alinjak, T.; Pavić, I.; Stojkov, M. Improvement of backward/forward sweep power flow method by using modified breadth-first search strategy. IET Gener. Transm. Distrib. 2017, 11, 102-109. [CrossRef]

19. Hameed, F.; Al-Hosani, M.; Zeineldin, H.H. A Modified Backward/Forward Sweep Load Flow Method for Islanded Radial Microgrids. IEEE Trans. Smart Grid 2017. [CrossRef]

20. Theo, W.L.; Lim, J.S.; Ho, W.S.; Hashim, H.; Lee, C.T. Review of distributed generation (DG) system planning and optimisation techniques: Comparison of numerical and mathematical modelling methods. Renew. Sustain. Energy Rev. 2017, 67, 531-573. [CrossRef]

21. Salman, S.; Tan, S. Investigation into protection of active distribution network with high penetration of embedded generation using radial and ring operation mode. In Proceedings of the IEEE International Universities Power Engineering Conference UPEC, Northumbria University, Newcastle, UK, 6-8 September 2006. [CrossRef]

22. D'adamo, C.; Abbey, C.; Baitch, A. Development and operation of active distribution networks: Results of CIGRE C6.11 working group. In Proceedings of the International Conference and Exhibition on Electricity Distribution CIRED, Frankfurt, Germany, 6-9 June 2011. Paper 0311.

23. Yu, W.; Liu, D.; Huang, Y.; Abbey, C. Operation optimization based on the power supply and storage capacity of an active distribution network. Energies 2013, 6, 6423-6438. [CrossRef]

24. Pilo, F.; Jupe, S.; Silvestro, F.; El Bakari, K.; Abbey, C.; Celli, G.; Taylor, J.; Baitch, A.; Carter-Brown, C. Planning and optimisation of active distribution systems-An overview of CIGRE Working Group C6.19 activities. In Proceedings of the CIRED Workshop, Lisbon, Portugal, 29-30 May 2012. [CrossRef]

25. Mohammed, N.; Ciobotaru, M.; Town, G. Online parametric estimation of grid impedance under unbalanced grid conditions. Energies 2019, 12, 4752. [CrossRef]

26. Hoffmann, N.; Fuchs, F.W. Minimal invasive equivalent grid impedance estimation in inductive-resistive power networks using extended Kalman filter. IEEE Trans. Power Electron. 2013, 29, 631-641. [CrossRef]

27. Mohammed, N.; Ciobotaru, M.; Town, G. Fundamental grid impedance estimation using grid-connected inverters: A comparison of two frequency-based estimation techniques. IET Power Electron. 2020, 13, 2730-2741. [CrossRef]

28. Xiang, Y.; Liu, J.; Li, F.; Liu, Y.; Liu, Y.; Xu, R.; Su, Y.; Ding, L. Optimal active distribution network planning: A review. Electr. Power Compon. Syst. 2016, 44, 1075-1094. [CrossRef]

29. Sultan, H.M.; Diab, A.A.Z.; Kuznetsov, O.N.; Ali, Z.M.; Abdalla, O. Evaluation of the Impact of High Penetration Levels of PV Power Plants on the Capacity, Frequency and Voltage Stability of Egypt's Unified Grid. Energies 2019, 12, 552. [CrossRef]

30. Radwan, A.A.; Foda, M.O.; Elsayed, A.M.; Mohamed, Y.S. Modeling and Reconfiguration of Middle Egypt Distribution Network. In Proceedings of the 19th IEEE International Middle East Power Systems Conference MEPCON, Cairo, Egypt, 19-21 December 2017. [CrossRef]

31. Wu, P.; Gu, J.; Qun, X.; Tao, Y. Distribution power flow calculation based on the load monitoring system. In Proceedings of the IEEE China International Conference on Electricity Distribution CICED, Shanghai, China, 5-6 September 2012. [CrossRef]

32. Wu, A.; Ni, B. Line Loss Analysis and Calculation of Electric Power Systems; John Wiley\& Sons Singapore Pte Ltd.: Singapore, 2016; ISBN 978-1-1188-6727-3. 
33. Huang, J.; Liu, M.; Zhang, J.; Dong, W.; Chen, Z. Analysis and field test on reactive capability of photovoltaic power plants based on clusters of inverters. J. Mod. Power Syst. Clean Energy 2017, 5, 283-289. [CrossRef]

34. Hill, L. Step type feeder voltage regulators. Trans. Am. Inst. Electr. Eng. 1935, 54, 154-158. [CrossRef]

35. Bishop, M.; Foster, J.D.; Down, D.A. The application of single-phase voltage regulators on three-phase distribution systems. In Proceedings of the IEEE Rural Electric Power Conference, Colorado Springs, CO, USA, 24-26 April 1994. [CrossRef]

36. International Electrotechnical Commission. IEC Standard 60076-21, Power Transformers-Part 21: Standard Requirements, Terminology, and Test Code for Step-Voltage Regulators; International Electrotechnical Commission: Geneva, Switzerland, 2011.

37. Kersting, W.H. The modeling and application of step voltage regulators. In Proceedings of the IEEE Power Systems Conference and Exposition PSCE, Seattle, WA, USA, 15-18 March 2009. [CrossRef]

38. Yan, R.; Li, Y.; Saha, T.; Wang, L.; Hossain, M. Modelling and Analysis of Open-Delta Step Voltage Regulators for Unbalanced Distribution Network with Photovoltaic Power Generation. IEEE Trans. Smart Grid 2016, 9 , 2224-2234. [CrossRef]

39. González-Morán, C.; Arboleya, P.; Mojumdar, R.R.; Mohamed, B. 4-Node Test Feeder with Step Voltage Regulators. Int. J. Electr. Power Energy Syst. 2018, 94, 245-255. [CrossRef]

40. Moghaddas-Tafreshi, S.; Mashhour, E. Distributed generation modeling for power flow studies and a three-phase unbalanced power flow solution for radial distribution systems considering distributed generation. Electr. Power Syst. Res. 2009, 79, 680-686. [CrossRef]

41. Teng, J.-H. Modelling distributed generations in three-phase distribution load flow. IET Gener. Transm. Distrib. 2008, 2, 330-340. [CrossRef]

42. Elsaiah, S.; Benidris, M.; Mitra, J. Analytical approach for placement and sizing of distributed generation on distribution systems. IET Gener. Transm. Distrib. 2014, 8, 1039-1049. [CrossRef]

43. Tah, A.; Das, D. Novel analytical method for the placement and sizing of distributed generation unit on distribution networks with and without considering P and PQV buses. Int. J. Electr. Power Energy Syst. 2016, 78, 401-413. [CrossRef]

44. Baran, M.E.; Wu, F.F. Optimal capacitor placement on radial distribution systems. IEEE Trans. Power Deliv. 1989, 4, 725-734. [CrossRef]

45. Jagtap, K.M.; Khatod, D.K. Loss allocation in radial distribution networks with various distributed generation and load models. Int. J. Electr. Power Energy Syst. 2016, 75, 173-186. [CrossRef]

46. Kersting, W.H. Radial distribution test feeders. In Proceedings of the IEEE Power Engineering Society Winter Meeting, Columbus, OH, USA, 28 January-1 February 2001; Volume 2, pp. 908-912. Available online: http://sites.ieee.org/pes-testfeeders/resources/ (accessed on 29 June 2019). [CrossRef]

47. Messenger, R.A.; Ventre, J. Photovoltaic Systems Engineering, 3rd ed.; CRC Press Taylor \& Francis Group: Boca Raton, FL, USA, 2010; ISBN 978-1-4398-0293-9.

48. Lynn, P.A. Electricity from Sunlight: An Introduction to Photovoltaics; John Wiley \& Sons: New York, NY, USA, 2011; ISBN 978-1-119-96503-9.

Publisher's Note: MDPI stays neutral with regard to jurisdictional claims in published maps and institutional affiliations.

(C) 2020 by the authors. Licensee MDPI, Basel, Switzerland. This article is an open access article distributed under the terms and conditions of the Creative Commons Attribution (CC BY) license (http://creativecommons.org/licenses/by/4.0/). 